\title{
TRAUMA NO PACIENTE PEDIÁTRICO
}

\author{
PEDIATRIC TRAUMA PATIENT
}

Gerson Alves Pereira Jr. ${ }^{1}$; Ana Claudia Andreghetto²; Aníbal Basile-Filho³ \& José Ivan de Andrade ${ }^{4}$

\begin{abstract}
${ }^{1}$ Médico Assistente da Unidade de Emergência do Hospital das Clínicas; ${ }^{2}$ Médica Residente (R4) de Ortopedia Pediátrica do Departamento de Cirurgia, Ortopedia e Traumatologia; ${ }^{3}$ Docente do Departamento de Cirurgia, Ortopedia e Traumatologia. Chefe da Disciplina de Terapia Intensiva; ${ }^{4}$ Docente do Departamento de Cirurgia, Ortopedia e Traumatologia. Coordenador do Serviço de Cirurgia da Unidade de Emergência do Hospital das Clínicas. Faculdade de Medicina de Ribeirão Preto da Universidade de São Paulo (FMRP- USP). CorResPondÊnciA: Dr. Gerson Alves Pereira Júnior - Rua Iguape, 747 apto 12 - C - Jardim Paulista - CEP 14090 - 000 - Ribeirão Preto SP - e-mail: gersonapj@netsite.com.br
\end{abstract}

PEREIRA JR GA; ANDREGHETTO AC; BASILE-FILHO A \& ANDRADE JI. Trauma no paciente pediátrico. Medicina, Ribeirão Preto, 32: 262-281, jul./set. 1999.

RESUMO: Este artigo revê os princípios do atendimento inicial ao traumatizado pediátrico, após uma revisão das características específicas da anatomia e fisiologia na infância. Aborda as diferentes situações através das quais o traumatizado pediátrico pode se apresentar e discute as opções que existem em cada fase do atendimento primário, bem como delineia os cuidados definitivos em lesões de alguns sistemas específicos.

UNITERMOS: Lesões. Pediatria. Traumatologia.

\section{INTRODUÇÃO}

O trauma permanece como a principal causa de morte e incapacidade nos pacientes pediátricos.

Nos Estados Unidos da América do Norte, uma dentre três crianças (cerca de 22 milhões) é, anualmente, vítima de trauma ${ }^{(1)}$. Em conseqüência, o trauma é responsável por aproximadamente $10 \%$ e $15 \%$, respectivamente, das internações pediátricas em hospitais e unidades de tratamento intensivo ${ }^{(2)}$. Para cada criança que morre, outras 40 crianças requerem hospitalização e 1000 necessitam de avaliação e tratamento de emergência ${ }^{(3)}$.

Cerca de $80 \%$ dos traumas são contusos, representados principalmente por acidentes por veículos a motor, bicicletas e quedas ${ }^{(4)}$.

Nos acidentes automobilísticos, as vítimas ou foram atropeladas ou ocupavam o veículo. Dentre os passageiros do veículo acidentado, as lesões mais comuns são os traumas cranioencefálicos e da coluna cervical. $\mathrm{O}$ uso adequado do cinto de segurança pode prevenir em 65 a $75 \%$ as lesões graves e os óbitos em passageiros menores de 04 anos de idade e 45 a $55 \%$ das lesões e mortes em pacientes pediátricos de qualquer idade ${ }^{(5)}$.

Ainda há o fato de que motoristas adolescentes são responsáveis por um número desproporcional de acidentes automobilísticos e lesões graves pela própria inexperiência associada ao uso do álcool, que está envolvido em $50 \%$ dos acidentes automobilísticos fatais $^{(5)}$.

Os atropelamentos são a principal causa de morte entre crianças de 05 a 09 anos, nos EUA. As vítimas de atropelamento comumente apresentam a tríade de Waddell: fratura de fêmur, trauma cranioencefálico e lesões do tronco ${ }^{(4)}$.

Os acidentes com bicicletas resultam em trauma cranioencefálico após queda do veículo em movimento sem o uso de capacete ou lesões viscerais do abdome superior associadas ao impacto contra o guidão ${ }^{(6)}$. O uso de capacetes para ciclistas pode prevenir $85 \%$ das lesões cranianas ${ }^{(5)}$. 
Quedas de alturas resultam em lesões cranianas, fratura de ossos longos e lesões do tronco, sendo sua gravidade diretamente relacionada à magnitude do deslocamento vertical ${ }^{(7)}$.

$\mathrm{O}$ afogamento é uma causa significante de mortes e sequelas neurológicas em crianças menores de 04 anos de idade. Para cada criança que morre devido a submersão, outras seis crianças são hospitalizadas e, aproximadamente, $20 \%$ dos sobreviventes terão sequela neurológica grave ${ }^{(5)}$.

Cerca de $80 \%$ das mortes por queimaduras ocorrem em acidentes domésticos. A inalação de fumaça, queimaduras por líquidos aquecidos e queimaduras elétricas afetam principalmente a criança menor de 04 anos de idade ${ }^{(5)}$.

As lesões penetrantes são mais freqüentemente fatais ${ }^{(4)} \mathrm{e}$, lamentavelmente, sua incidência vem aumentando ${ }^{(8)}$. As armas de fogo são responsáveis por um aumento do número de lesões acidentais e também por aumento do número de homcídios e suicídios na população pediátrica. $\mathrm{O}$ aumento na incidência de lesões por armas de fogo ocorre paralelamente a um aumento da disponibilidade de armas. Nos EUA, mais de 66\% das residências contêm armas de fogo e cerca de $34 \%$ dos alunos do primeiro e segundo graus referem um fácil acesso às armas, aumentando o registro de casos de crianças levando armas de fogo à escola ${ }^{(5)}$.

Nos EUA, para cada criança que morre devido a traumatismos de qualquer natureza, cerca de quatro crianças sofrem incapacidade permanente ${ }^{(9)}$. $\mathrm{O}$ custo estimado da atenção ao trauma, nas fases agudas e de reabilitação, é de 16 bilhões de dólares anuais ${ }^{(10)}$.

\section{PARTICULARIDADES GERAIS DO TRAU- MA NA INFÂNCIA}

Em comparação com os adultos, as crianças apresentam maior frequiência de lesões multissistêmicas. Isto decorre da maior absorção de energia por unidade de área, porque a massa corporal é menor. Além disso, o tecido adiposo é exíguo, o tecido conjuntivo tem menor elasticidade e os órgãos são mais próximos entre si ${ }^{(1,11)}$.

A relação entre superfície e volume corporais é elevada ao nascimento e diminui com o crescimento. Como resultado, a perda de calor torna-se um fator importante na criança. A hipotermia desenvolve-se rapidamente, em conseqüência da exposição da criança às temperaturas ambientais e da infusão de líquidos endovenosos na reposição volêmica que, de preferência, devem estar aquecidos ${ }^{(1,11)}$.
Nas crianças mais jovens, a instabilidade emocional frequientemente leva a um comportamento regressivo na presença de estresse, dor ou a percepção de um ambiente hostil. A capacidade de a criança interagir com pessoas desconhecidas e a situações diferentes é limitada, especialmente na presença de dor ${ }^{(11)}$.

Diferentemente dos adultos, as crianças necessitam recuperar-se dos efeitos do trauma e continuar o processo de crescimento e desenvolvimento futuros. As lesões, mesmo que de pequena monta, podem levar a um período prolongado de incapacidade, às custas de reações de natureza emocional ou orgânica, repercutindo, inclusive, na capacidade de aprendizado $^{(12,13)}$.

Tardiamente, distúrbios sociais, afetivos e do aprendizado podem ser identificados em metade das crianças vítimas de trauma grave.

O trauma pediátrico desarranja a estrutura familiar, com conseqüentes distúrbios emocionais e comportamentais, além de financeiros. Cerca de dois terços dos irmãos de uma criança traumatizada apresentam distúrbios emocionais e afetivos ${ }^{(11)}$. Freqüentemente, ocorrem distúrbios entre os pais, os quais podem culminar com a separação do casal ${ }^{(11)}$.

Todos estes problemas tornam indispensável uma assistência psicológica à criança e à sua família.

\section{PARTICUlaRidades aNATÔMICAS E FISIOLÓGICAS}

Devido à imaturidade da sua estrutura anatômica e de sua resposta fisiológica, o politraumatizado pediátrico requer atenções especiais na sua avaliação inicial $^{(1)}$.

O crânio oferece uma proteção inadequada para o cérebro da criança e os traumatismos cranioencefálicos podem produzir lesão cerebral grave, principalmente no primeiro ano de vida ${ }^{(14)}$.

O cérebro dobra de tamanho nos primeiros 06 meses de vida e atinge $80 \%$ do tamanho do cérebro adulto aos 02 anos de idade ${ }^{(11)}$. Apresenta um maior conteúdo aquoso e sua mielinização ainda não está completa. Sendo que a mielina ajuda a proporcionar estrutura ao cérebro, a sua falta torna-o mais homogêneo e muito mais susceptível às lesões difusas ${ }^{(14)}$.

As lesões difusas do encéfalo, particularmente o edema e a lesão axonal difusa, são mais comuns na criança do que em qualquer outra faixa etária ${ }^{(4)}$. O edema está associado à perda da autorregulação da pressão arterial, resultando em anóxia (por paralisia vasomotora arteriolar e aumento do volume sangüíneo encefálico e aumento da pressão intracraniana). 
Em contraste, lesões focais por contusão ou laceração, que ocorrem adjacentes a proeminências ósseas (geralmente em lobos temporal e frontal) e, hemorragia intracraniana importante (epidural, subdural ou hematomas intraparenquimatosos) são incomuns e, quando presentes, têm pequeno volume, insuficiente para justificar a evacuação cirúrgica ${ }^{(4)}$.

A maior relação entre o tamanho da cabeça e o restante do corpo torna mais provável uma lesão cervical, particularmente em traumatismos cranioencefálicos e traumas multissistêmicos. No entanto, a lesão medular é menos freqüente em crianças do que em adultos. De todas as lesões cervicais, $5 \%$ ocorrem em crianças $^{(1)}$. É mais freqüiente em subluxações atlantaxial (C1 - C2) ou na junção atlantoccipital até a fase préescolar e, lesões mais baixas (C5 - C7) na idade esco$\operatorname{lar}(4,5)$ As lesões que se situam acima das raízes nervosas, responsáveis pela maior parte da inervação diafragmática $(\mathrm{C} 4)$, predispõe à parada respiratória e à tetraplegia ${ }^{(4)}$. A subluxação (com ou sem deslocamento) e a fratura do odontóide são bem mais comuns que a lesão do corpo vertebral ${ }^{(4)}$. As diferenças anatômicas responsáveis por estas particularidades são: ligamentos interespinhosos e cápsulas articulares mais flexíveis; articulação uncinada pobremente desenvolvida e incompleta; corpos vertebrais encunhados anteriormente com tendência ao escorregamento lateral com a flexão; facetas articulares planas; cabeça relativamente grande em relação aos adultos com maior angulação durante a flexão ou extensão, resultando em maior transferência de energia ${ }^{(1,4)}$.

A pseudo-subluxação (deslocamento anterior de $\mathrm{C} 2 \mathrm{em} \mathrm{C} 3$ ) é vista em $40 \%$ das crianças menores de 07 anos. Apenas 20\% apresentam esta particularidade até os 16 $\operatorname{anos}^{(1,11)}$ (ver Figura 1)

Os centros de crescimento esquelético podem simular fraturas: a sincondrose odontóide basilar aparece como área radiolucente na base da lâmina, principalmente em menores de 05 anos; a epífise odontóide apical aparece como separação vista entre 05 e 11 anos; as extremidades dos processos espinhosos podem simular fraturas ${ }^{(1,11)}$.

As vias aéreas representam a mais importante diferença anatômica entre crianças e adultos em relação ao trauma ${ }^{(4)}$. Quanto menor a criança, maior a desproporção entre o tamanho do crânio e da face, sendo mais posterior a faringe e maior a força passiva de flexão cervical $^{(1)}$. Os tecidos moles (língua, tonsilas palatinas) são relativamente maiores, quando comparados com a cavidade oral, o que dificulta a visualização da laringe e facilita a obstrução completa da via aérea pela queda posterior da língua ${ }^{(1,4)}$. A laringe da criança tem maior angulação anterocaudal, dificultando sua visualização para canulação $\operatorname{direta}^{(1)}$.

As crianças são respiradores nasais primários até os 06 meses de idade. A maior resistência no fluxo aéreo ocorre ao nível das narinas. $\mathrm{O}$ batimento de asa de nariz é um indicador confiável de insuficiência respiratória em criança ${ }^{(14)}$.

As vias aéreas pediátricas são mais estreitas em todos os níveis, principalmente no nível da cartilagem cricóide e, são mais facilmente obstruídas por muco, sangue ou corpos estranhos e pelos próprios tecidos moles da cavidade oral, especialmente no trauma cranioencefálico ${ }^{(4)}$.

A traquéia tem aproximadamente $5 \mathrm{~cm}$ de extensão e cresce para $7 \mathrm{~cm}$ aos 18 meses, o que au-

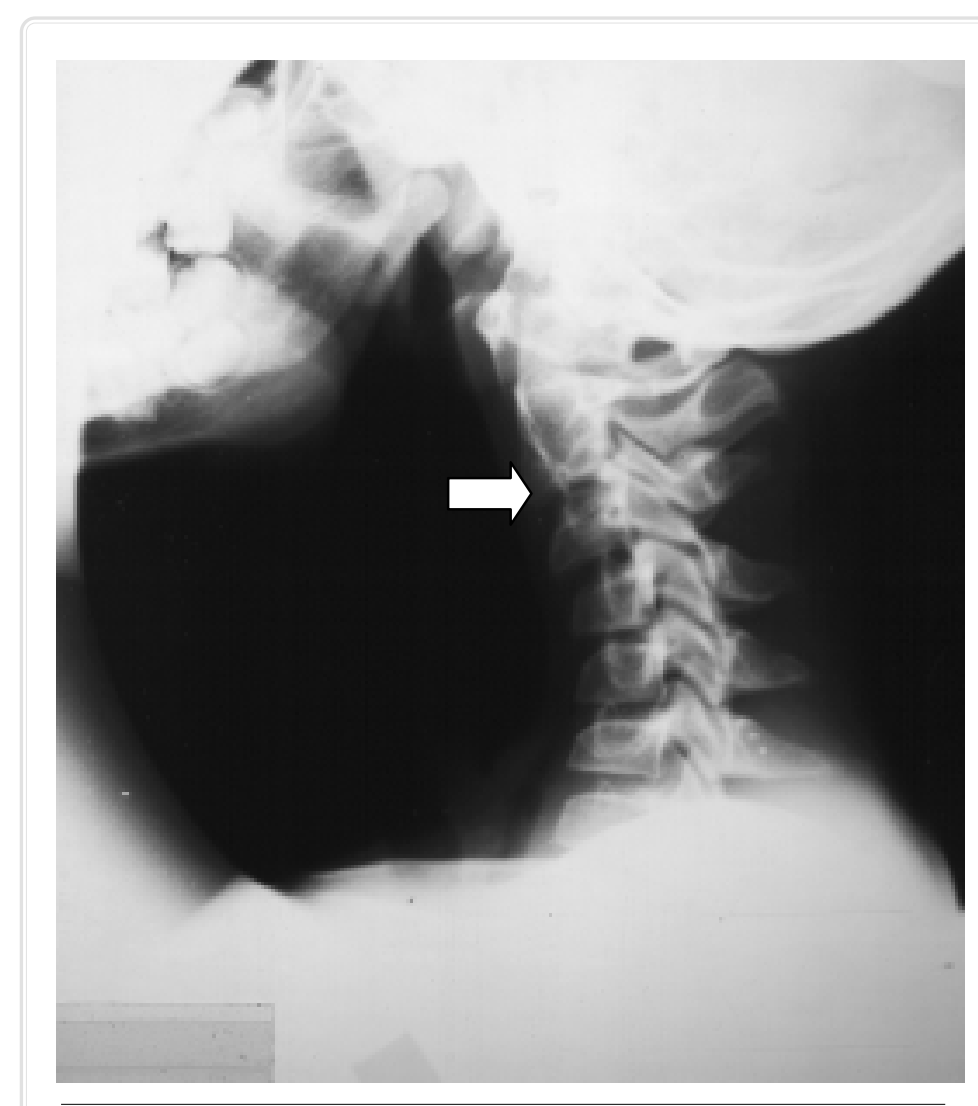

Figura 1: Radiografia de coluna cervical em perfil, mostrando a pseudosubluxação C2 - C3 (veja a seta). 
menta o risco de intubação seletiva ${ }^{(1,8)}$, que pode ocorrer com igual frequiência à direita e à esquerda, diferentemente do adulto, cuja intubação seletiva direita é mais freqüente devido a maior horizontalização do bronquiofonte direito ${ }^{(14)}$.

O trauma pediátrico grave é mais uma desordem das vias aéreas e ventilação do que da circulação ${ }^{(4)}$. A parada cardíaca pediátrica geralmente é um evento secundário ao desenvolvimento de choque circulatório progressivo ou insuficiência respiratória, com hipóxia e acidose concomitantes ${ }^{(14)}$.

A etiologia da parada cardiorrespiratória em crianças é mais comumente relacionada a uma desordem respiratória primária, diferentemente da dos adultos, em que a principal etiologia é por desordens cardíacas. A parada respiratória descoberta a tempo em uma criança, tendo ainda os pulsos arteriais centrais palpáveis, supõe uma sobrevida de 60 a $70 \%$ e a grande maioria dos sobreviventes não apresenta sequelas do ponto de vista neurológico ${ }^{(14)}$.

Na caixa torácica, a estrutura óssea é mais cartilaginosa em crianças, tendo maior complacência. O aumento de pressão intratorácica, durante a insuficiência respiratória, é menos eficiente em aumentar o volume corrente, porque o tórax se retrai, reduzindo o volume corrente e, indiretamente, aumentando o trabalho da ventilação. A retração dos tecidos moles, similarmente, reduz o volume torácico durante esforços respiratórios vigorosos. Assim, na criança até a fase pré-escolar, o volume corrente é muito dependente do movimento do diafragma ${ }^{(14)}$.

As costelas estão alinhadas em um plano mais horizontal, o que diminui o deslocamento inspiratório do tórax no plano anteroposterior. Os pontos de inserção muscular do diafragma, no tórax, também são horizontais na criança, levando a menor excursão diafragmática durante a inspiração, reduzindo o volume inspiratório, principalmente na presença de distensão abdominal e cirurgia ${ }^{(14)}$.

Os músculos intercostais são imaturos e não podem manter a ventilação ativa por vários anos após o nascimento, aumentando a dependência da função e excursão do diafragma ${ }^{(14)}$.

Contusões pulmonar e miocárdica podem ocorrer sem fraturas costais ou outros sinais de trauma. A presença de fraturas costais sugere grande transferência de energia, comumente associada a lesões viscerais graves ${ }^{(1,4)}$.

O tórax flácido e o pneumotórax hipertensivo (a lesão com maior potencial de letalidade) aumentam o risco de comprometimento ventilatório e circulatório na criança, devido à maior mobilidade mediastinal ${ }^{(4,8)}$.

A capacidade de compensação da insuficiência respiratória é limitada pelos seguintes fatores: maior consumo de oxigênio ( 2 a 3 vezes o do adulto); menor reserva funcional (que torna a criança mais susceptível à hipóxia); menor complacência pulmonar; maior complacência da parede torácica (que resulta em taquipnéia em resposta à hipóxia); maior horizontalização das costelas e musculatura intercostal rudimen$\operatorname{tar}^{(4,14)}$. A cianose é um pobre indicador de hipóxia, particularmente na criança anêmica, pois tem menor nível de hemoglobina e a cianose ocorre apenas quando um nível crítico de hemoglobina reduzida $(5 \mathrm{~g} / \mathrm{dL})$ está presente. Assim, o conteúdo sangüíneo de oxigênio deve cair a níveis muito baixos antes da cianose ser evidente ${ }^{(5,14)}$.

A diferença fisiológica fundamental em relação ao adulto é a capacidade da criança de compensar os transtornos hemodinâmicos induzidos pelo choque hemorrágico, mantendo a pós-carga devido à vasoconstricção periférica (o que mantém a perfusão dos órgãos vitais $)^{(4)}$. O volume sangüíneo circulante e o débito cardíaco são maiores por quilograma de peso do que os adultos, porém os valores absolutos são menores devido ao menor tamanho do corpo ${ }^{(14)}$.

O débito cardíaco é grandemente dependente da alta freqüência cardíaca, uma vez que o volume sistólico é baixo devido ao pequeno tamanho do coração. A bradicardia pode limitar muito a perfusão sistêmica e constitui-se um sinal de hipóxia grave ou acidose. Lembrar que, se apesar de oxigenação e ventilação fornecidas, uma criança menor de 02 anos tiver freqüência cardíaca menor que $80 \mathrm{bpm}$ ou uma criança maior que 02 anos tiver uma freqüência cardíaca menor que $60 \mathrm{bpm}$, devemos iniciar as manobras de compressões torácicas da ressuscitação cardiopulmonar ${ }^{(14,15)}$.

A freqüência cardíaca deve ser sempre valorizada em função da idade e do quadro clínico da criança. Quanto menor a idade e maior a alteração, mais elevada será a freqüência cardíaca ${ }^{(5,11,14,15)}$. (ver Tabela I).

A criança permanece normotensa e com boa perfusão tecidual até a perda de 25 a $30 \%$ do volume sangüíneo ${ }^{(1,4)}$. Esta grande capacidade de preservação da estabilidade hemodinâmica decorre da derivação do fluxo sangüíneo dos tecidos periféricos. Isto resulta em metabolismo anaeróbio e acidose láctica, aumentando o trabalho ventilatório e diminuindo a contratilidade miocárdica, o que limita esta resposta compensatória por um período prolongado ${ }^{(4)}$. 


\begin{tabular}{|llcccc|}
\hline \multicolumn{6}{|l|}{ Tabela I - Sinais vitais nos pacientes pediátricos } \\
\hline Grupos etários & $\begin{array}{c}\text { Peso } \\
(\mathrm{kg})\end{array}$ & $\begin{array}{c}\text { Freqüência } \\
\text { cardíaca }(\mathrm{bpm})\end{array}$ & $\begin{array}{c}\text { Pressão arterial } \\
\text { Sistólica }(\mathrm{mmHg})\end{array}$ & $\begin{array}{c}\text { Freqüência } \\
\text { respiratória (ipm) }\end{array}$ & $\begin{array}{c}\text { Débito urinário } \\
(\mathrm{mL} / \mathrm{kg} / \mathrm{hora})\end{array}$ \\
\hline até os 06 meses & $3-6$ & $160-180$ & $60-80$ & 60 & 2 \\
Lactentes & 12 & 160 & 80 & 40 & 1,5 \\
Pré-escolares & 16 & 120 & 90 & 30 & 1 \\
Adolescentes & 35 & 100 & 100 & 20 & 0,5 \\
\hline
\end{tabular}

A resposta primária à hipovolemia na criança é a taquicardia, que também pode ocorrer por dor, medo ou estresse emocional ${ }^{(1)}$.

A taquicardia, a má perfusão periférica e a diminuição da pressão de pulso são fundamentais para o diagnóstico do choque circulatório ${ }^{(1,11)}$. A melhor evidência clínica de diminuição da perfusão tecidual é a palidez cutânea, o enchimento capilar prolongado e a frialdade de extremidades. O enchimento capilar prolongado (mais de 02 segundos) pode ser causado por choque, febre ou ambientes frios. $\mathrm{Na}$ avaliação do enchimento capilar, a extremidade deve ser elevada acima do nível do coração para assegurar que se esteja avaliando o enchimento dos capilares arteriolares e não a estase venosa. A hipotensão arterial aparece tardiamente e indica estado de choque descompensado, perda sanguínea grave, com ressuscitação inadequada, levando ao risco de parada cardiorrespiratória iminente $\mathrm{e}^{(1,4,14)}$.

Reavaliações freqüentes são imperativas no reconhecimento precoce do choque circulatório na criança $^{(1)}$.

Como regra, a pressão sistólica em crianças deve ser $80 \mathrm{mmHg}$ mais 02 vezes a idade em anos e a pressão diastólica deve ser $2 / 3$ da pressão sistólica ${ }^{(1)}$.

A hipotensão arterial é definida como pressão sistólica menor que $70 \mathrm{mmHg}$ mais 2 vezes a idade em $\operatorname{anos}^{(4)}$.

O volume sangüíneo circulante é de 8 a $9 \%$ do peso corpóreo, porém em valores absolutos tal volume é pequeno, portanto, devemos valorizar qualquer $\operatorname{perda}^{(11)}$.

O menor tamanho do abdome predispõe a ocorrência de lesões múltiplas em traumas contusos ${ }^{(4)}$. As costelas flexíveis e a fina parede abdominal proporcionam pouca proteção aos órgãos parenquimatosos (que são proporcionalmente maiores na criança) do abdome superior, aumentando a incidência de lesões, inclusive do pâncreas (pancreatite ou pseudocisto traumático $)^{(4)}$. As lesões costumam ser mais profundas e ex- tensas, porque os órgãos possuem cápsula mais espessa e elástica. Pela mesma razão, a hemorragia cessa espontaneamente com maior frequiência, facilitando o tratamento conservador não operatório das lesões ${ }^{(4)}$.

A dilatação gástrica aguda, devida à aerofagia, predispõe a criança ao comprometimento ventilatório pela limitação da mobilidade diafragmática, maior risco de aspiração e ao estímulo vagal, que pode mascarar a taquicardia em resposta à hipovolemia ${ }^{(4,8,11)}$.

O periósteo mais espesso e mais elástico e a cortical óssea altamente porosa e vascular, associados a maior quantidade proporcional de matriz protéica em relação ao seu conteúdo mineral, torna a constituição óssea mais maleável, justificando a ocorrência de fraturas incompletas (torus e fratura em galho verde) e completas sem desvio ${ }^{(4)}$. (ver Figuras 2 e 3 )

Outros fatores que diferenciam o trauma esquelético pediátrico são: rápida taxa de cicatrização; tendência à remodelação da fratura, exceto no plano rotacional; alta incidência de lesões vasculares, particularmente no cotovelo, que, embora não representem risco imediato de perda do membro, podem ocasionar contratura isquêmica; baixa incidência de lesões ligamentares associadas; distúrbios a longo prazo do crescimento em fraturas que envolvem a cartilagem de conjugação e a diáfise de ossos longos ${ }^{(4,11)}$.

As fraturas de ossos longos mais comuns são do fêmur e tíbia, secundárias a atropelamentos, compondo a tríade de Waddell, juntamente com o trauma cranioencefálico e as lesões do tronco ${ }^{(4)}$. As fraturas de ossos longos em crianças podem estar associadas a grandes sangramentos, já que as partes moles não tamponam adequadamente a hemorragia ${ }^{(1)}$.

As perdas insensíveis de água são maiores do que nos adultos em virtude da maior relação entre a área de superfície e a massa corpórea. Os estoques de glicogênio são pequenos e, associados a maior taxa metabólica, fazem com que a hipoglicemia seja comum em situações de estresse. Uma infusão contínua de glicose é necessária ${ }^{(14)}$. 


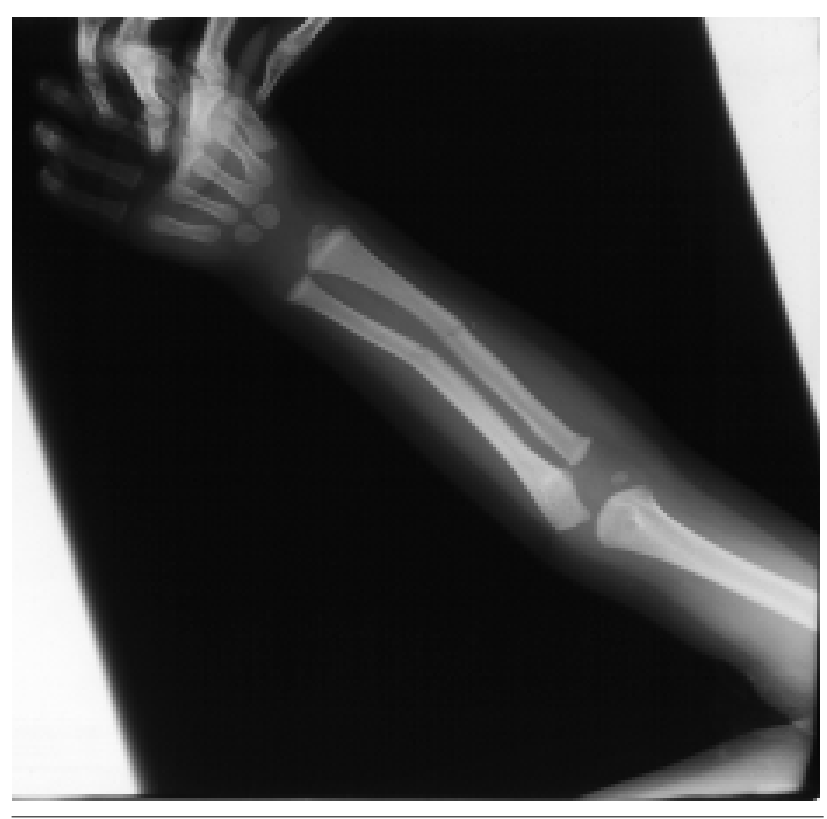

Figura 2: Radiografia em posição anteroposterior, mostrando uma fratura de antebraço "em galho verde".

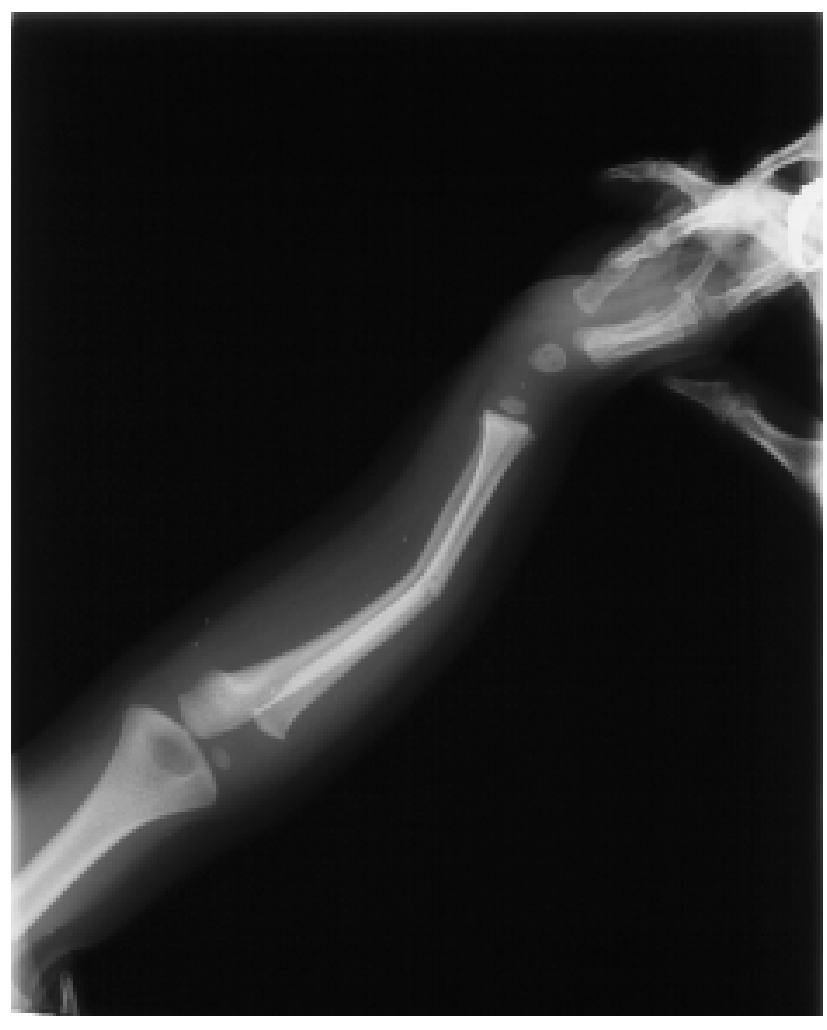

Figura 3: Radiografia em perfil, mostrando uma fratura de antebraço "em galho verde".

O débito urinário aceitável para uma criança bem hidratada é de $02 \mathrm{ml} / \mathrm{kg} /$ hora para crianças menores de 2 anos e de $1 \mathrm{ml} / \mathrm{kg} /$ hora para crianças maiores $^{(11,14)}$. (ver Tabela I)

\section{SISTEMA DE ATENDIMENTO MÉDICO DE EMERGÊNCIA}

Assim como no adulto, a sobrevida de crianças envolvidas em emergências médicas traumáticas ou não traumáticas é bastante influenciada por um adequado sistema de emergência pré-hospitalar. Este sistema é responsável pela identificação das emergências, liberação de veículos e recursos humanos adequados para aquele tipo de emergência, atendimento (em tempo) na cena e encaminhamento para o hospital mais próximo e mais preparado para o atendimento daquela emergência específica, mediante contato prévio com a equipe médica que irá recepcionar o caso.

Devido ao significante potencial de recuperação plena das crianças traumatizadas, os cuidados devem começar o mais breve possível após o trauma, de preferência na cena do acidente.

Há várias etapas que devem ser bem equacionadas para uma boa eficiência do serviço de atendimento de emergência na fase pré-hospitalar.

- Reconhecimento do problema.

- Acessar o sistema de emergência.

- Providenciar os primeiros socorros.

Normalmente, a identificação da emergência é feita pelos próprios pais e familiares, que devem saber da existência e de como acessar o sistema de atendimento médico de emergência. Devem saber relatar adequadamente o fato ocorrido e saber iniciar os cuidados ou receber informações de como iniciar os cuidados até a chegada da equipe de atendimento pré-hospitalar. Este contato é crítico e as comunidades devem se esforçar para que o nível cultural de sua população permita a melhor eficiência nesta comunicação, assim como a melhor qualidade de primeiros socorros possa ser prestada por quem identificou a emergência.

A equipe que presta serviços na fase pré-hospitalar, seja ela composta ou não por um médico, deve ter conhecimento e experiência na abordagem do paciente pediátrico.Protocolos de atendimento devem existir para uma padronização e melhor eficiência desse atendimento. Todos os veículos devem conter equipamentos específicos e apropriados para qualquer tipo de intervenção que venha a estar indicada a estes pacientes.

$\mathrm{Na}$ fase pré-hospitalar ou no atendimento num hospital de pequeno porte, as crianças com trauma multissistêmico ou com risco de mortalidade significativo [Escala de trauma pediátrico ${ }^{(15)}$ de 8 ou menos ou RTS (Revised Trauma Score) ${ }^{(16)}$ de 11 ou menos] devem, se possível, ser encaminhadas para hospitais com recursos materiais disponíveis e recursos humanos habituados no tratamento do trauma pediátrico grave(Ver Tabelas II e III) 


\begin{tabular}{|c|c|c|c|}
\hline \multicolumn{4}{|c|}{ Tabela II - Escore de trauma pediátrico (PTS - Pediatric Trauma Score) ${ }^{(15)}$} \\
\hline \multirow[b]{2}{*}{ Componente avaliado } & \multicolumn{3}{|c|}{ Escores } \\
\hline & +2 & +1 & -1 \\
\hline Peso (kg) & $>20$ & $10-20$ & $<10$ \\
\hline Vias aéreas & normal & técnica de manutenção, $0_{2}$ & via aérea definitiva \\
\hline Pressão arterial sistólica mmHg) & $>90$ & $\begin{array}{l}50 \text { - 90, pulsos carotídeos e } \\
\text { femorais palpáveis }\end{array}$ & $\begin{array}{l}<50 \text {,pulsos filiformes ou } \\
\text { ausentes }\end{array}$ \\
\hline Nível de consciência & alerta & $\begin{array}{l}\text { obnubilado ou qualquer } \\
\text { alteração }\end{array}$ & coma \\
\hline Fratura & nenhum & simples, fechada & múltipla, exposta \\
\hline Pele & nenhum & contusão ou laceração $<7$ cm & perda de tecido \\
\hline \multicolumn{4}{|c|}{$\begin{array}{l}\text { As vias aéreas são avaliadas não como uma função, mas como uma descrição de qual o cuidado requerido para uma adequada } \\
\text { abordagem. } \\
\text { Como um índice preditor de lesões, todas as crianças com PTS menor que } 08 \text { devem ser encaminhadas para um local apropriado de } \\
\text { atendimento a crianças traumatizadas }\end{array}$} \\
\hline
\end{tabular}

\begin{tabular}{|c|c|c|}
\hline \multicolumn{3}{|c|}{$\begin{array}{l}\text { Tabela III - Escore de trauma revisada } \\
\text { (RTS - Revised Trauma Score) }\end{array}$} \\
\hline Parâmetros & Variáveis & Escores \\
\hline \multirow{5}{*}{$\begin{array}{l}\text { A) Freqüência respiratória } \\
\text { (ipm) }\end{array}$} & $10-29$ & 4 \\
\hline & $>29$ & 3 \\
\hline & $6-9$ & 2 \\
\hline & $1-5$ & 1 \\
\hline & 0 & 0 \\
\hline \multirow{5}{*}{$\begin{array}{l}\text { B) Pressão arterial } \\
\text { sistólica }(\mathrm{mmHg})\end{array}$} & $>89$ & 4 \\
\hline & $76-89$ & 3 \\
\hline & $50-75$ & 2 \\
\hline & $1-49$ & 1 \\
\hline & 0 & 0 \\
\hline \multirow{5}{*}{$\begin{array}{l}\text { C) Escala de Coma de } \\
\text { Glasgow }\end{array}$} & $13-15$ & 4 \\
\hline & $9-12$ & 3 \\
\hline & $6-8$ & 2 \\
\hline & $4-5$ & 1 \\
\hline & $<4$ & 0 \\
\hline \multicolumn{3}{|c|}{ TOTAL $=$ Escores de $(A+B+C)$} \\
\hline
\end{tabular}

\section{ATENDIMENTO INICIAL}

É similar à abordagem dada ao adulto. A atenção inicial deve ser dirigida para a manutenção da permeabilidade das vias aéreas, ventilação e circulação, incluindo o controle do sangramento, tratamento do choque circulatório e das lesões torácicas com risco iminente de vida ${ }^{(1,4)}$.

Também é importante que um cirurgião qualificado e experiente no manuseio do trauma pediátrico esteja envolvido precocemente nas fases iniciais da ressuscitação ${ }^{(17,18)}$, pois as principais causas de iatrogenias que afetam a mortalidade no trauma pediátri$\mathrm{co}^{(19)}$, em adição à inadequada reposição volêmica inicial, têm sido a falha em se reconhecer o sangramento interno (intracraniano e intra-abdominal) em tempo hábil, atrasando o tratamento operatório e a falha em reconhecer a ausência de sangramento interno, promovendo perigosa hiper-hidratação ${ }^{(4,18,19)}$.

\subsection{Avaliação primária e reposição volêmica}

A avaliação e o suporte das funções cardiopulmonares são aspectos fundamentais da avaliação primária, realizada durante os minutos iniciais do atendimento ao trauma. Ao mesmo tempo em que as funções cardiopulmonares são avaliadas, um rápido exame físico toraco-abdominal deve ser realizado para se detectar em lesões torácicas que causem risco imediato de vida ou quaisquer outras condições que interfiram com o sucesso do restabelecimento das funções vitais $^{(5)}$.

A padronização proposta pelo ATLS (Advanced Trauma Life Support) consiste na sistematização do atendimento em fases sucessivas: 1) avaliação primária e restabelecimento das funções vitais; 2 ) medidas adicionais; 3) avaliação secundária; 4) reavaliação e 5) tratamento definitivo ${ }^{(1,11)}$. 
Na avaliação primária, o ATLS utiliza o seguinte método mnemônico ${ }^{(11)}$ :

A) (Airway maintenance with cervical spine control): Manutenção da permeabilidade das vias aéreas e estabilização da coluna cervical.

B) (Breathing and ventilation): Manutenção da respiração e ventilação.

C) (Circulation with hemorrhage control): Estabilização circulatória com controle da hemorragia externa.

D) (Disability - neurological status): Avaliação da incapacidade e exame neurológico sumário.

E) (Exposure/Enviromental): Exposição completa do paciente, com controle da temperatura ambiental.

A avaliação e reanimação inapropriadas são identificadas como a principal causa de mortes evitáveis na população pediátrica. Os erros mais comuns são: a falha em abrir e manter a via aérea permeável; falha na reposição volêmica adequada, especialmente em crianças com traumatismo cranioencefálico e a falha em reconhecer e tratar as hemorragias internas ${ }^{(5)}$.

\subsection{Vias aéreas e estabilização da coluna cervical}

O objetivo é restaurar ou manter a oxigenação tecidual adequada.

A obstrução imediata das vias aéreas ou a parada respiratória pode se desenvolver na criança com traumatismo cranioencefálico grave, devido a três mecanismos: ${ }^{(5)}$

- oclusão das vias aéreas superiores devido à queda da língua com fechamento da epiglote, que ocorre quando a criança perde a consciência;

- transecção da coluna cervical com parada respiratória subseqüente;

- contusão cerebral.

A primeira consideração no manuseio das vias aéreas é a posição da cabeça. A criança com alteração do nível de consciência ou que é incapaz de manter uma posição confortável da cabeça, deve ser colocada na "posição do cheirador" (em superfície rígida, rodando a cabeça para trás, de modo que a face da criança esteja dirigida para cima) para minimizar a obstrução das vias aéreas superiores pelos tecidos moles. Se a criança estiver consciente, ela deve escolher a sua posição de conforto e não deve ser forçada a ficar numa posição diferente ${ }^{(14)}$.

Na criança traumatizada, respirando espontaneamente, com mecanismo de trauma onde a lesão de coluna cervical seja possível, a cabeça deve ser mantida em posição neutra e a patência da via aérea deve ser assegurada pelo pelas manobras de elevação do mento (chin lift) ou tração da mandíbula (jaw thrust) ${ }^{(1)}$. Após limpeza e aspiração da boca e orofaringe, o oxigênio deve ser administrado em altas concentrações.

Se o paciente estiver inconsciente, os métodos mecânicos para manutenção da permeabilidade das vias aéreas ou mesmo uma via aérea definitiva podem ser necessários, como o uso da cânula orofaríngea ou cânula de Guedel ${ }^{(11)}$.

É fundamental que se use a cânula de tamanho adequado, ou seja, do mento ao ângulo da mandíbula.

A introdução da cânula de Guedel na direção do palato duro, e, posteriormente, promovendo sua rotação de 180 graus, não é recomendada em crianças. Deve ser introduzida suavemente em direção à orofaringe ${ }^{(1)}$. Pode-se usar também um abaixador de língua. Como no adulto, não deve ser usado na criança consciente.

Se não se conseguir manter uma boa oxigenação através destas técnicas de manutenção da permeabilidade das vias aéreas (avaliada pela oximetria de pulso), deve-se partir para o estabelecimento de uma via aérea definitiva, onde colocamos uma cânula endotraqueal, adequadamente fixada e conectada a um respirador mecânico.

A via aérea definitiva pode ser conseguida através de um tubo endotraqueal (oro ou nasotraqueal) ou de uma via aérea cirúrgica (cricotireoidostomia por punção ou cirúrgica, ou traqueostomia) ${ }^{(1,5,11)}$.

As indicações para intubação endotraqueal na criança traumatizada são:(5)

- parada respiratória;

- insuficiência respiratória (hipoventilação e hipoxemia arterial; apesar da suplementação de oxigênio e/ou acidose respiratória);

- obstrução de vias aéreas;

- coma - escala de coma de Glasgow ou escala de coma pediátrico de Adelaide menor ou igual a 8;

- necessidade de suporte ventilatório prolongado (lesões torácicas ou necessidade de estudos radiológicos prolongados).

A intubação orotraqueal é o modo mais confiável de ventilação na criança com a via aérea comprometida e deve ser realizada com adequada imobilização e proteção da coluna cervical $^{(1,4,8,11)}$.

Tubos endotraqueais de tamanho adequado e sem balonete (cuff) (até os 08 anos de idade) devem ser usados para evitar edema subglótico, ulceração e ruptura da frágil via aérea. $\mathrm{O}$ menor diâmetro das vias aéreas está ao nível da cartilagem cricóide, que forma um selo natural com o tubo endotraqueal ${ }^{(1,11,14)}$. 
Uma técnica simples para escolher o tamanho do tubo adequado para a criança a ser intubada é o diâmetro externo da narina ou do dedo mínimo da mão. O tamanho correto do tubo endotraqueal é determinado mais pelo diâmetro do anel da cartilagem cricóide do que pela abertura glótica. Normalmente, no paciente intubado com tubo de tamanho apropriado, observase um escape de ar quando se ministra uma pressão inspiratória positiva de 20 a $30 \mathrm{~cm} \mathrm{H}_{2} \mathrm{O}$. Se não for observada a passagem de ar com tais pressões, pode ser que o tubo seja muito grande e pode causar complicações pós-extubação, como edema e estenose subglótica ${ }^{(14)}$.

Há várias outras maneiras de se estimar o tamanho correto do tubo endotraqueal, como a fórmula que se segue, usada para crianças maiores de 02 anos: ${ }^{(5)}$

$$
\text { Tubo endotraqueal }(\mathrm{mm})=\frac{\text { Idade }(\mathrm{em} \text { anos })}{4}+4
$$

A maioria dos centros de trauma utilizam um protocolo medicamentoso de seqüência rápida de intubação. Assim, as crianças que requerem a intubação endotraqueal devem, primeiro, ser pré-oxigenadas e receber sulfato de atropina $(0,02 \mathrm{mg} / \mathrm{kg}$ - dose mínima de 0,1 e máxima de $0,5 \mathrm{mg}$ ) para assegurar que a frequiência cardíaca permanecerá elevada, já que a frequiência cardíaca é o principal determinante do débito cardíaco na criança e a estimulação mecânica das vias aéreas ou a hipoxemia pode induzir bradiarritmia. A seguir, devem ser sedadas, sendo que, para isso, podemos utilizar o tiopental (4 a $5 \mathrm{mg} / \mathrm{Kg}$ ), se estiverem normovolêmicas ou, midazolam $(0,1 \mathrm{mg} / \mathrm{Kg}$, com máximo de $5 \mathrm{mg}$ ), se estiverem hipovolêmicas. Após a sedação, a pressão sobre a cartilagem cricóide (manobra de "Sellick") é mantida para se evitar a aspiração de conteúdo gástrico. Neste momento, faz-se o uso de bloqueadores neuromusculares que podem ser: succinilcolina $(2 \mathrm{mg} / \mathrm{Kg}$ para menores de $10 \mathrm{Kg}$ e 1 $\mathrm{mg} / \mathrm{Kg}$ para maiores de $10 \mathrm{Kg}$ ), que é um agente de curta duração e é considerado a droga de escolha ou, vencurônio, que é um agente de ação mais prolongada, o que pode ser benéfico em certas situações, como no caso de realização de exames complementares. O uso destas drogas deve ser feito de acordo com o julgamento clínico e o nível de prática e experiência de quem vai manuseá-las ${ }^{(11,20)}$.

Ao se realizar a intubação orotraqueal, pode ser difícil o controle da posição da língua e, em crianças menores de 20 quilos, é aconselhável o uso de lâmina reta no laringoscópio, devendo ser longa o bastante para atingir a epiglote e permitir a visualização das cordas vocais $^{(21)}$.

Após passar a abertura glótica, o tubo endotraqueal deve ser posicionado 2 a $3 \mathrm{~cm}$ abaixo do nível da corda vocal ${ }^{(11,21)}$. Neste momento, pode-se retirar a pressão sobre a cartilagem cricóide ${ }^{(11,21)}$.

Uma regra utilizada, em crianças maiores de 2 anos, para se estimar o comprimento adequado de introdução do tubo endotraqueal, desde a arcada dentária superior até o meio da traquéia, é:(5)

Comprimento $(\mathrm{cm})=\underline{\text { Idade }(\mathrm{em} \text { anos })}+12$ 2

Alternativamente, a distância de inserção, em centímetros, a partir da arcada dentária superior, pode ser estimada, multiplicando-se o diâmetro interno (em $\mathrm{mm}$ ) do tubo endotraqueal por $3^{(5)}$.

Deve-se auscultar o tórax bilateralmente nas axilas para evitar intubação seletiva. Porém, em virtude de fácil transmissão do murmúrio respiratório através da parede torácica, a posição da cânula orotraqueal deve ser, tão logo seja possível, confirmada pela radiografia de tórax ${ }^{(8,11,21)}$.

Qualquer movimento da cabeça pode deslocar o tubo, sendo necessário avaliar periodicamente se a cânula permanece em posição apropriada ${ }^{(11,21)}$.

A intubação nasotraqueal não deve ser realizada na criança traumatizada abaixo de 12 anos, pois requer passagem, às cegas, através de ângulo agudo na nasofaringe em direção anterior e caudal para entrar na glote, o que torna esta via difícil. Também a penetração inadvertida no crânio ou lesão de tecidos moles da nasofaringe apresentam riscos consideráveis na criança ${ }^{(11,21)}$.

Após várias tentativas frustradas de se obter uma via aérea definitiva (geralmente, a intubação orotraqueal) ou quando não se dispõe de material adequado ou pessoal habilitado para tal procedimento ou ainda na presença de trauma facial grave com necessidade imediata de uma via aérea definitiva, partimos para a realização de uma via aérea cirúrgica (cricotireoidostomia por punção ou cirúrgica, ou traqueostomia).

A cricotireoidostomia não deve ser realizada, por via cirúrgica, em crianças menores de 12 anos $^{(1)}$.

A cricotireoidostomia por punção permite a oxigenação por, no máximo, 30 a 45 minutos. O acúmulo progressivo de dióxido de carbono impossibilita o uso do método além desse período, especialmente no trauma cranioencefálico ${ }^{(1)}$.

Na técnica da cricotireoidostomia por punção, fazemos a antissepsia e anestesia da região cervical 
anterior, localizamos a membrana cricotireóidea, fixamos a traquéia em virtude da sua grande mobilidade e fazemos uma punção com "abocath" apropriado (catéter venoso 16 ou 18), em direção caudal a $45^{\circ}$ do plano anterior, conectado a uma seringa contendo soro fisiológico, que deve ser mantida em aspiração durante todo o procedimento, para certificarmos da introdução do catéter no lúmen traqueal. Ao aspirar ar, retiramos a agulha e mantemos o cateter no local ${ }^{(1,21)}$ (ver Figura 4).

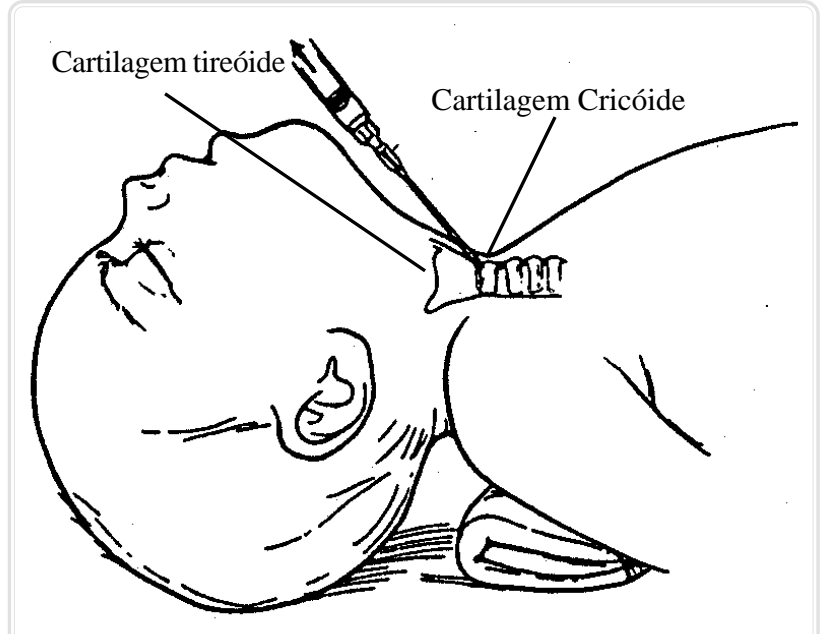

Figura 4: Cricotireoidostomia por punção.

A ventilação com pressão positiva é feita com extensão de borracha numa fonte de oxigênio que forneça $100 \mathrm{ml} / \mathrm{kg} /$ minuto, num total de 1 a $5 \mathrm{~L} /$ minuto, para minimizar o potencial de barotrauma. Devemos fazer um orifício lateral na borracha ou usar um mecanismo em Y para controlar o tempo inspiratório e expiratório. Como a expiração é mais difícil por este método, mantemos uma relação inspiração : expiração de 1: 4. A expiração é feita pelo orifício lateral ou do Y e também através da região supraglótica. Se notarmos a ausência de saída ou a saída de pequena quantidade de ar pela boca e nariz, na expiração, com o tórax excursionando pouco durante a inspiração e mantendo-se progressivamente insuflado, devemos diminuir a fonte de oxigênio à metade ou estabelecer uma pausa entre as insuflações para permitir a expiração passiva e procurar estabelecer mais rapidamente uma via aérea definitiva, pelo risco de barotrauma ${ }^{(1,21)}$.

Outras maneiras de fazermos a insuflação de ar através de punção cricotireóide seriam: a) dispositivo mecânico de insuflação de gás e b) conexão de uma seringa de $3 \mathrm{ml}$ (sem o êmbolo) no cateter e adaptação à seringa do intermediário da cânula orotraqueal $\mathrm{n}^{\circ} 6$, que permite a conexão com o $\mathrm{Ambu}^{(14)}$.

Após este procedimento, dependendo da situação que motivou a sua indicação (falta de material adequado ou pessoal habilitado no momento, trauma facial grave, etc), podemos partir para a intubação orotraqueal ou traqueostomia.

A estabilização da coluna cervical em posição neutra impede a potencial lesão da medula espinhal. Na criança pequena, é necessário a colocação de um coxim debaixo do tronco e extremidades, já que o occipício proeminente força o pescoço para uma ligeira flexão na posição supina sobre uma superfície plana ${ }^{(4)}$.

No caso da realização de cricotireoidostomia cirúrgica (em crianças maiores de 12 anos), após a abertura da membrana cricotireóidea, colocamos uma cânula de traqueostomia ou mesmo uma cânula traqueal comum, porém adequadamente fixada para evitar intubação seletiva. Idealmente, nas primeiras 24 horas ou, no máximo em 72 horas, deve ser convertida numa traqueostomia para se evitar estenose de traquéia.

A traqueostomia é um procedimento que leva tempo para a sua realização e tem riscos potenciais graves de lesões de estruturas importantes que passam pela região cervical. Sua única indicação na emergência é a presença de fratura de laringe (clinicamente, o paciente apresenta-se com rouquidão e enfisema subcutâneo cervical), quando não é factível a realização da cricotireoidostomia. No procedimento, não retiramos a porção anterior do anel traqueal como no adulto, sendo feita uma incisão em cruz, no terceiro anel da traquéia, para a introdução da cânula.

\subsection{Ventilação}

O volume corrente é de 7 a $10 \mathrm{ml} / \mathrm{Kg}$ e a frequiência respiratória depende da idade (ver Tabela I). $\mathrm{Na}$ hora de ventilar, não se esquecer do volume corrente adequado, principalmene quando se usa o $\mathrm{AMBU}$, pois as vias aéreas são frágeis e imaturas com risco de barotrauma ${ }^{(4,17)}$.

A grande distensibilidade do tórax em crianças faz com que o mesmo se expanda facilmente, quando aplicamos ventilação com pressão positiva (via bolsa e máscara ou por ventilação mecânica). Se a parede torácica não se elevar visivelmente durante a ventilação com pressão positiva, o apoio ventilatório não está adequado $^{(14,17)}$.

A hipoventilação é a causa mais comum de parada cardíaca na criança e a anormalidade acidobásica 
mais comum é a acidose causada por hipoventilação, que precede a parada cardíaca $\left.{ }^{(5,17}\right)$.

A presença de fraturas costais indica que ocorreu um traumatismo torácico grave e que podem ocorrer lesões de outros órgãos, tais como do fígado, baço e pulmões ${ }^{(5,11)}$.

As duas lesões, que mais comumente impedem, a estabilização inicial de crianças com trauma são o pneumotorax hipertensivo e o pneumotorax aberto ${ }^{(5)}$.

As lesões pleurais (hemo ou pneumotórax) ocorrem com igual frequiência em adultos e crianças. $\mathrm{O}$ pneumotórax hipertensivo requer alívio imediato pelo risco iminente de $\mathrm{vida}^{(4,8)}$. O diagnóstico é confirmado pela introdução de uma agulha no $2^{\circ}$ espaço intercostal, na linha hemiclavicular. A saída de ar confirma a suspeita clínica. O cateter deve ser mantido na posição e o tórax deve ser drenado no $5^{\circ}$ espaço intercostal (na linha do mamilo) entre as linhas axilares média e anterior. A exploração digital após a abertura da cavidade pleural e antes da introdução do dreno é necessária para certificarmos de que não há aderências pleurais e excluir a presença de vísceras abdominais em posição anômala, como no caso de ruptura diafragmática ${ }^{(11)}$.

Os tubos de drenagem torácica têm seu diâmetro escolhido de acordo com a idade, sendo, em geral, usado o de $12 \mathrm{~F}$ no lactente, o de $20 \mathrm{~F}$ na criança menor que $30 \mathrm{Kg}$ e o de $28 \mathrm{~F}$ no adolescente $^{(6)}$. Se necessário colocá-los em aspiração, usamos a pressão de $10 \mathrm{~cm}$ de água no infante e de $20 \mathrm{~cm}$ de água na criança maior ${ }^{(8)}$.

O pneumotórax aberto resulta de um ferimento penetrante do tórax que permite um fluxo bidirecional de ar entre o hemitórax afetado e o ar ambiente (normalmente, tal ferimento deve ter, pelo menos, dois terços do diâmetro da traquéia). Isto impede uma ventilação efetiva por levar a um equilíbrio das pressões intra e extratorácica, resultando num desvio paradoxal do mediastino para o lado contralateral, em cada respiração espontânea. $O$ tratamento a ser realizado é a ventilação com pressão positiva, curativo oclusivo de três pontas para ocluir o ferimento e ainda permitir a saída de ar durante a expiração e a subseqüente drenagem pleural, a não ser que o defeito seja tão grande que torne necessário o reparo cirúrgico ${ }^{(5)}$.

A toracotomia está indicada em casos de hemotórax com drenagem de sangue contínua de 2 a $4 \mathrm{ml} / \mathrm{Kg} /$ hora $^{(8)}$.

O oxímetro de pulso deve ser usado continuamente no atendimento à criança traumatizada, devendo-se usar o probe adequado ${ }^{(3)}$.

\subsection{Circulação}

\subsubsection{Acesso venoso}

Devemos estabelecer, pelo menos, dois acessos venosos (no mínimo de calibre 20 ou 22) na criança gravemente traumatizada ${ }^{(1,11)}$.

Numa situação de emergência, quando necessitamos da infusão imediata de adrenalina, atropina, lidocaína ou naloxone, numa criança sem qualquer acesso venoso, tais medicamentos podem ser utilizados por via intratraqueal, numa dose de 2 a $2,5 \mathrm{x}$ a dose usual ${ }^{(14,17)}$.

Os acessos percutâneos preferidos estão na mão, fossa antecubital e safena no tornozelo. A veia femoral deve ser evitada em crianças devido à alta incidência de trombose venosa e possibilidade de perda do membro isquêmico ${ }^{(1,11)}$.

Se tais acessos não forem conseguidos após duas tentativas, devemos considerar a infusão intraóssea em crianças menores que 6 anos e a dissecção venosa nas demais ${ }^{(1)}$.

Na dissecção venosa, os locais preferidos são: safena magna no tornozelo, veia basílica no cotovelo, veia cefálica principal mais alta no braço e veia jugular externa ${ }^{(1,8)}$.

A grande dificuldade de obtenção rápida de acesso venoso em crianças menores que 06 anos, particularmente aqueles que não possuem sinais vitais, motivou o desenvolvimento da infusão intra-óssea. As bases anatômicas e fisiológicas da infusão intra-óssea foram estabelecidas em 1922, sendo empregada, clinicamente, pela primeira vez, em 1934, no tratamento da anemia perniciosa ${ }^{(22)}$. O método ganhou grande aceitação na década de $40^{(23 / 26)}$, porém caiu no ostracismo nas décadas seguintes, até que na década de 80 voltou a ser utilizado ${ }^{(27,28,29)}$.

Qualquer droga ou solução que possa ser administrada por via endovenosa, também pode ser infundida por via intra-óssea. Assim, podem ser utilizadas por esta via: adrenalina, bicarbonato de sódio, cloreto de cálcio, soluções cristalóides e colóides, sangue e derivados, aminas vasoativas e as soluções empregadas em hiperalimentação parenteral ${ }^{(11,14)}$.

A via intra-óssea é rápida e efetiva, com tempo menor que 20 segundos para atingir a circulação sistêmica.A razão desta eficiência é que os vasos intramedulares e os lagos venosos são protegidos por paredes ósseas rígidas e não colabáveis, que se mantêm pérvias, mesmo durante o choque ou parada cardíaca, e que têm comunicação direta e extensa com a circulação sistêmica ${ }^{(28,29)}$. 
O local preferido para infusão intra-óssea (cateter curto 16 ou 18). é a tíbia proximal (cerca de 1 a $3 \mathrm{~cm}$ abaixo de sua tuberosidade e medialmente ao platô tibial) com introdução da agulha em direção distal (para não lesar a cartilagem de crescimento).Outros sítios possíveis de obtenção do acesso intra-ósseo são: 1) fêmur distal ( $1 \mathrm{~cm}$ acima da patela na linha média) com introdução da agulha em direção cranial, 2) maléolo lateral ou medial e as cristas ilíacas. A via esternal não é aconselhada pelo risco de transfixação do osso com perfuração cardíaca e dos grandes vasos. A infusão intra-óssea não deve ser realizada distalmente a um sítio de fratura ${ }^{(1,11,14)}$.

Os passos técnicos são os seguintes: 1) posicionar a criança em decúbito dorsal; 2) identificar uma extremidade sem lesão; 3 ) fletir o joelho, permitindo o repouso do calcanhar sobre o leito; 4) colocar um coxim sob o joelho; 5) definir o local de punção; 6) antissepsia $\mathrm{e}$, se a criança estiver consciente, infiltração anestésica local; 7) introduzir a agulha de punção de medula óssea curta, lisa ou com rosca ou agulha de punção peridural curta, de calibre 18, com o mandril, o bisel da agulha deve ser voltado para o pé, a agulha, deve ser introduzida perpendicularmente à superfície óssea; 8) avançar a agulha através do cortex e para dentro da medula óssea por meio de movimentos de rotação e pressionando-a firme, mas delicadamente; 9) remover o mandril e conectar a uma seringa de $10 \mathrm{ml}$, com cerca de $5 \mathrm{ml}$ de cloreto de sódio a $0,9 \%$, aspirandose medula óssea; 10) conectar a agulha a um equipo e iniciar a infusão de líquidos ${ }^{(11,14)}$. (ver Figura 5).

Para checar o adequado posicionamento para infusão intra-óssea, podemos observar os seguintes

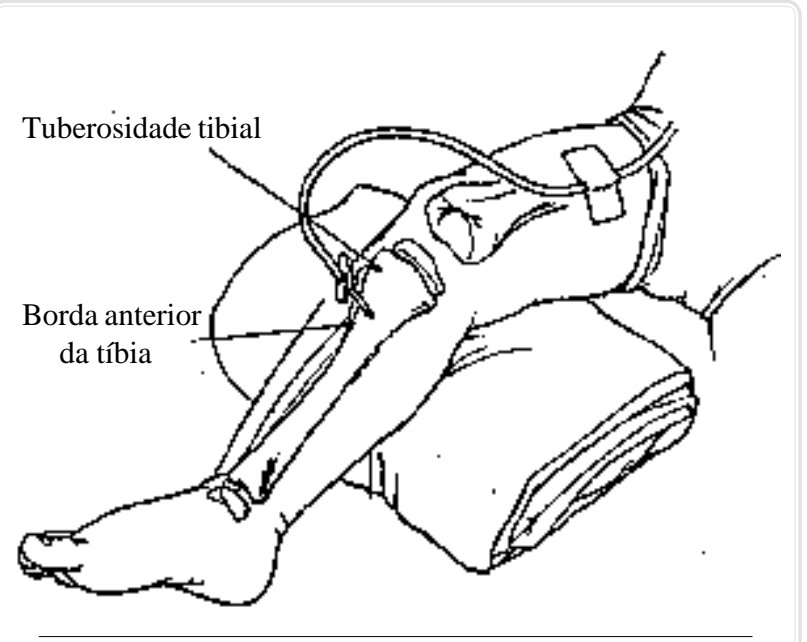

Figura 5: Técnica de punção intraóssea. sinais: 1) verificar a sensação de queda da resistência oferecida à infusão; 2) depois de introduzida, a agulha permanece em posição, sem a necessidade de nenhum apoio e não pode ser deslocada facilmente; 3 ) aspirar a medula óssea (de aspecto gelatinoso e avermelhado, que contém gotas de gordura); 4) fácil infusão de fluidos, sem extravazamento para tecidos moles ou edema. Muitos autores desaconselham a aspiração de medula óssea pelo risco de entupimento da agulha. Um curativo oclusivo deve ser usado para a proteção da agulha ${ }^{(11,14,29)}$.

É importante salientar que a punção intra-óssea deve ser abandonada tão logo um acesso venoso periférico adequado for estabelecido, de preferência dentro das primeiras duas horas ${ }^{(1)}$. Após a descontinuação desta via e retirada da agulha, deve ser aplicada uma pressão no sítio de punção por, pelo menos, 05 minutos, e deixado com curativo oclusivo estéril ${ }^{(14)}$.

As contra-indicações da punção intra-óssea são poucas: fratura, infecção local, punção prévia, interrupção vascular prévia de origem traumática ou cirúrgica. Um membro no qual a flebotomia esteja sendo tentada não deve ser usado para infusão intra-óssea ${ }^{(14)}$.

As complicações deste procedimento incluem: abscesso e celulite local, hematomas, síndrome de compartimento, infiltração de fluidos no periósteo e/ou subcutânea, dor e, raramente, osteomielite $(0,6 \%)^{(1,10,13)}$.

Foi demonstrado que a infusão intra-óssea não leva a alterações do crescimento do osso em desenvolvimento. Uma complicação clínica rara e, provavelmente, sem maiores repercussões é a ocorrência de embolia gordurosa pulmonar, porém não se mostraram alterações da $\mathrm{pO}_{2}$ arterial ou de "shunt" pulmonar, durante um estudo experimental ${ }^{(29)}$.

A cateterização percutânea de veia central está sujeita a complicações freqüentes, em um paciente hipovolêmico, e está contra-indicada nesta fase do atendimento.

Assim que for conseguido um acesso venoso, amostras de sangue devem ser enviadas para tipagem, prova-cruzada, contra-prova e exames bioquími$\cos ^{(1,4,8)}$.

\subsubsection{Reposição volêmica}

A taquicardia, a má perfusão periférica e a diminuição da pressão de pulso são fundamentais para o diagnóstico do choque circulatório ${ }^{(1)}$. A melhor evidência clínica de diminuição da perfusão tecidual é a palidez cutânea, o enchimento capilar prolongado e a frialdade de extremidades ${ }^{(11,14)}$. (ver Tabela IV). 


\begin{tabular}{|llll|}
\hline \multicolumn{4}{|c}{ Tabela IV - Respostas sistêmicas à perda sangüínea no paciente pediátrico } \\
\hline \multicolumn{1}{|c|}{ Sistemas } & Perda sangüínea $<25 \%$ & $\begin{array}{l}\text { Perda sangüínea } \\
\text { entre 25 e } 45 \%\end{array}$ & Perda sangüínea $>45 \%$ \\
\hline Cardiovascular & $\begin{array}{l}\text { Pulso filiforme, aumento } \\
\text { da freqüência cardíaca }\end{array}$ & $\begin{array}{l}\text { Aumento da freqüência } \\
\text { cardíaca }\end{array}$ & $\begin{array}{l}\text { Hipotensão, taquicardia ou } \\
\text { bradicardia }\end{array}$ \\
$\begin{array}{l}\text { Sistema } \\
\text { Nervoso }\end{array}$ & $\begin{array}{l}\text { Letárgico, irritado, } \\
\text { confuso }\end{array}$ & $\begin{array}{l}\text { Alteração no nível de } \\
\text { consciência, pouca } \\
\text { resposta à dor }\end{array}$ & Comatoso \\
Pele & Fria & $\begin{array}{l}\text { Fria, cianótica, diminuição } \\
\text { do enchimento capilar }\end{array}$ & Fria e pálida \\
Rins & $\begin{array}{l}\text { Riminuição do débito } \\
\text { urinário }\end{array}$ & $\begin{array}{l}\text { Redução maior do débito } \\
\text { urinário }\end{array}$ & Não há diurese \\
\hline
\end{tabular}

Uma queda de $25 \%$ da volemia é necessária para a manifestação clínica de choque. A associação de taquicardia, extremidades frias e pressão arterial sistólica menor que $70 \mathrm{mmHg}$ claramente indica choque $^{(1,4)}$. A hipotensão arterial na criança representa um estado de choque descompensado e indica uma perda sanguiínea maior que $45 \%$ do volume circulante ${ }^{(11)}$.

O risco de parada cardiopulmonar está presente em qualquer criança que demonstre insuficiência respiratória, redução do nível de consciência e cianose ou palidez cutânea. Os sinais clínicos de choque e insuficiência respiratória resultam da disfunção orgânica causada pela hipóxia e acidose. Estes sinais incluem taquicardia, alteração do nível de consciência (irritabilidade ou letargia), oligúria, hipotonia, pulsos centrais fracos ou pulsos periféricos ausentes e enchimento capilar prolongado, apesar de adequada temperatura ambiental. A bradicardia, hipotensão e respirações irregulares são sinais $\operatorname{tardios}^{(5)}$.

$\mathrm{Na}$ suspeita de choque, devemos usar hidratação endovenosa em bolo com fluidos aquecidos, sempre que possível. O aquecimento dos fluidos intravenosos pode ser feito até a temperatura de $39^{\circ}$ $\mathrm{C}$, normalmente utilizando o aquecedor de líquidos ou o microondas para o aquecimento dos cristalóides e o sangue através da passagem pelo aquecedor ${ }^{(1,11)}$. Usamos $20 \mathrm{ml} / \mathrm{Kg}$ da solução de lactato de Ringer $(25 \% \text { da volemia estimada da criança })^{(1)}$.

$\mathrm{O}$ retorno à estabilidade hemodinâmica é representado por alguns parâmetros ${ }^{(1)}$ : frequiência cardíaca < 130 bpm; aumento da pressão arterial > 20 $\mathrm{mmHg}$; aquecimento das extremidades; melhora do sensório; diurese $>1 \mathrm{ml} / \mathrm{Kg} / \mathrm{hora}$; aumento da pressão arterial sistólica $>80 \mathrm{mmHg}^{(1,11)}$.

Essa mesma dose de solução cristalóide deve ser repetida, se a criança não se estabiliza prontamente, o que aumenta a suspeita de hemorragia contínua $^{(1,11)}$. Já que o objetivo é repor o volume intravascular perdido, podem ser necessários três "bolus" de $20 \mathrm{ml} / \mathrm{Kg}$ para atingir a reposição de $25 \%$ da volemia, pois a regra do 3:1 (cada $\mathrm{ml}$ de sangue perdido é reposto com $3 \mathrm{ml}$ de cristalóide, para permitir a restituição do volume plasmático perdido para os espaços intersticial e intracelular) aplica-se, também, ao paciente pediátrico, assim como ao adulto ${ }^{(11)}$.

Se houver hipotensão franca (choque descompensado) ou a criança responder pobremente ou transitoriamente às duas infusões de solução cristalóide $(40 \mathrm{ml} / \mathrm{Kg})$ e estiver iniciando o terceiro "bolus" de $20 \mathrm{ml} / \mathrm{Kg}$, devemos transfundir papas de hemácias do sangue tipo específico ou $\mathrm{O}$ negativo (se não estiver pronta a tipagem) na dose de $10 \mathrm{ml} / \mathrm{Kg}$ e a criança deve ser preparada para a cirurgia, mantendo o hematócrito em torno de $30 \%$, dependendo da idade ${ }^{(11)}$. A hemotransfusão está indicada sempre que a criança não responde à fluidoterapia inicial, para melhor fornecimento de oxigênio aos tecidos. Na criança que se estabilizou rapidamente, a infusão de líquidos deve ser controlada para manter um débito urinário de 1 a $2 \mathrm{ml} / \mathrm{kg}$ (dependendo da idade) e a hemotransfusão indicada quando o hematócrito estiver abaixo de $20 \%$, dependendo da idade ${ }^{(1,4)}$.

Após a estabilização hemodinâmica, a fluidoterapia de manutenção deve obedecer à formula de Holliday $^{(30)}$. (ver Tabela V) ou a qualquer outro método de hidratação que oriente a manutenção da volemia. 


$\begin{aligned} & \text { Tabela V - Necessidades hídricas diárias em } \\
& \text { função do peso corporal na infância, segundo a } \\
& \text { fórmula de Holliday }(30)\end{aligned}$
\begin{tabular}{ll} 
Peso corporal & Necessidades hídricas diárias \\
\hline até $10 \mathrm{~kg}$ & $100 \mathrm{ml} / \mathrm{kg}$ \\
10 a $20 \mathrm{~kg}$ & $1000 \mathrm{ml}+50 \mathrm{ml} / \mathrm{kg}(10-20 \mathrm{~kg})$ \\
20 a $30 \mathrm{~kg}$ & $1500 \mathrm{ml}+20 \mathrm{ml} / \mathrm{kg}(20-30 \mathrm{~kg})$ \\
\hline
\end{tabular}

Na fase de avaliação primária ou reavaliação, executam-se a sondagem nasogástrica (ou orogástrica, se houver trauma facial ou sinais de fratura de base do crânio) e a sondagem vesical. As contra-indicações da sondagem vesical são uretrorragia, hematoma na base do escroto ou fratura de bacia com deslocamento da sínfise púbica ${ }^{(4,11)}$. Na sondagem vesical, são usadas as sondas de calibre $8 \mathrm{~F}$, nas crianças menores de 02 anos, 10F, na criança maior, e $14 \mathrm{~F}$, no adolescente ${ }^{(8)}$.

Nesta fase, também fazemos o controle da hemorragia externa por pressão direta sobre o ferimento, se houver a necessidade ${ }^{(1)}$.

\subsection{Exame neurológico}

Devido à limitada resposta verbal em crianças, na avaliação neurológica sumária usamos a Escala de Coma Pediátrico de Adelaide ${ }^{(31)}$, que, na presença de escore menor ou igual a 8, indica intubação traqueal e hiperventilação $^{(1,4,5,11)}$ (ver Tabela VI).

Pode ser empregada também a escala de coma de Glasgow (32) (ver Tabela VII), porém, nas crianças menores de 04 anos, deve-se mudar o escore verbal. (ver Tabela VIII) Lembrar que, no paciente intubado, inconsciente ou numa fase pré-verbal, a parte mais importante desta escala é a resposta motora ${ }^{(5,11)}$.

Como no adulto, a hipotensão jamais deve ser atribuída ao traumatismo cranioencefálico e outras fontes de hemorragia devem ser exaustivamente investigadas.Lembrar que, na criança, embora infreqüente, a hipotensão pode ocorrer por perda sanguínea em ferimentos do couro cabeludo ${ }^{(1,11)}$.

\subsection{Exposição completa e controle da temperatura}

A maior razão entre a superfície corpórea e o volume corporal aumenta as trocas de calor com o ambiente e afeta diretamente a capacidade da criança em regular a temperatura. A pouca espessura da pele e a falta de tecido subcutâneo desenvolvido contribui para o aumento da perda de calor por evaporação ${ }^{(1,4)}$.

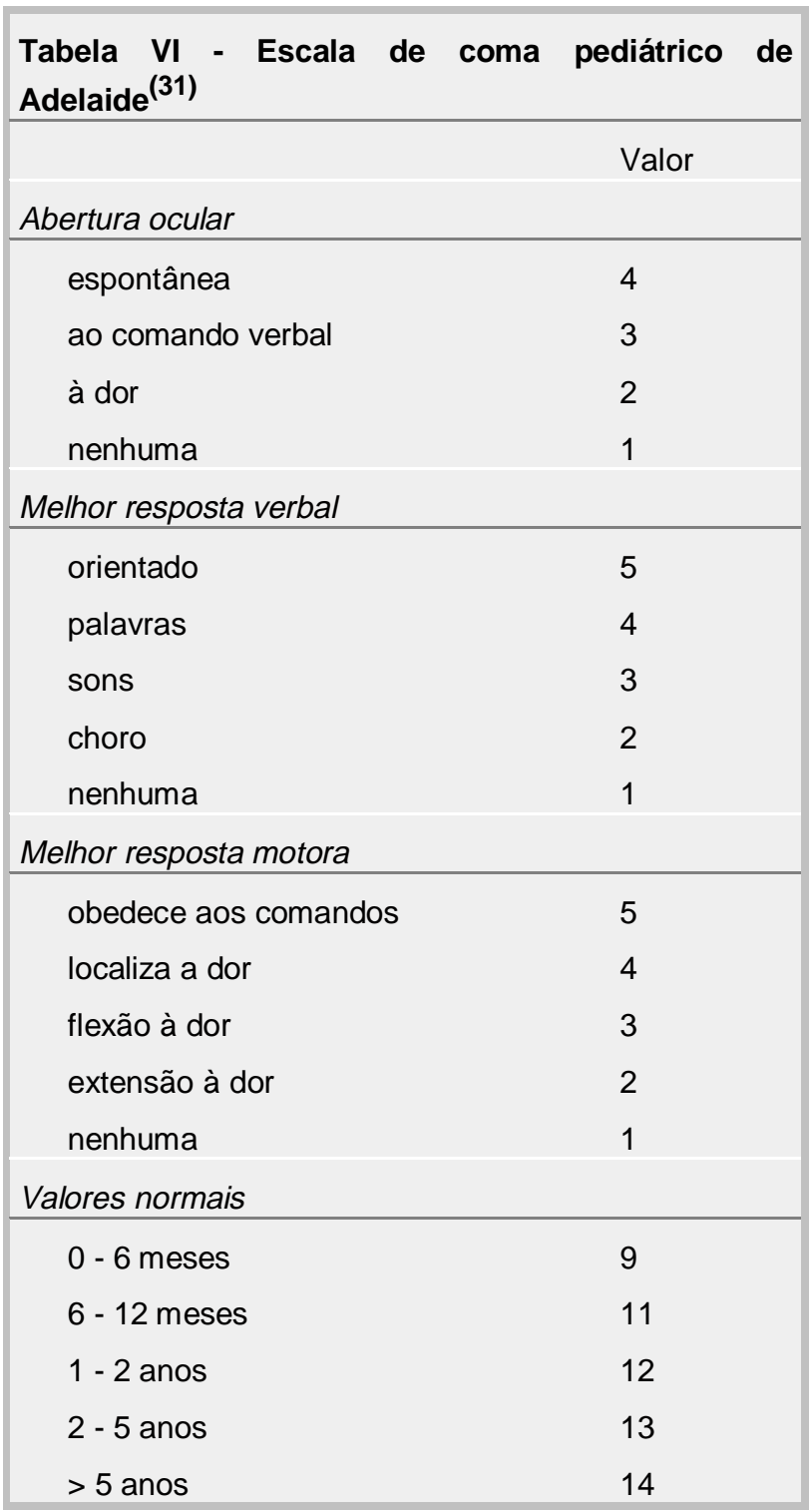

A hipotermia prolonga o tempo de coagulação e afeta adversamente a função do sistema nervoso central ${ }^{(4)}$.

Lâmpadas de calor e colchões térmicos podem ser necessários para manter a temperatura corpórea. $\mathrm{O}$ aquecimento da sala de admissão e dos fluidos intravenosos é necessário para preservar o calor do $\operatorname{corpo}^{(1)}$.

\subsection{Avaliação secundária}

Um cuidadoso exame da cabeça aos pés, como no adulto, é fundamental nesta fase de avaliação do politraumatizado e deve abordar todos os sistemas e incluir os exames bioquímicos e a avaliação radiológica ${ }^{(1,4,11)}$. 


\begin{tabular}{|c|c|}
\hline \multicolumn{2}{|c|}{ Tabela VII - Escala de coma de Glasgow ${ }^{(32)}$} \\
\hline & Valor \\
\hline \multicolumn{2}{|l|}{ Abertura ocular } \\
\hline espontânea & 4 \\
\hline ao comando verbal & 3 \\
\hline aos estímulos dolorosos & 2 \\
\hline nenhuma & 1 \\
\hline \multicolumn{2}{|l|}{ Melhor resposta verbal } \\
\hline orientada & 5 \\
\hline confusa & 4 \\
\hline palavras inapropriadas & 3 \\
\hline sons incompreensíveis & 2 \\
\hline nenhuma & 1 \\
\hline \multicolumn{2}{|l|}{ Melhor resposta motora } \\
\hline obedece aos comandos & 6 \\
\hline localiza o estímulo doloroso & 5 \\
\hline retirada ao estímulo doloroso & 4 \\
\hline flexão anormal (decorticação) & 3 \\
\hline extensão anormal (descebração) & 2 \\
\hline nenhuma & 1 \\
\hline TOTAL & $3-15$ \\
\hline
\end{tabular}

\begin{tabular}{lc}
$\begin{array}{l}\text { Tabela VIII - Modificação da escala de coma de } \\
\text { Glasgow para a resposta verbal em crianças } \\
\text { menores de } 04 \text { anos }\end{array}$ \\
\hline \multicolumn{1}{|c|}{ Resposta verbal } & Valor \\
\hline Palavras apropriadas ou sorriso social & 5 \\
Choro, mas consolável & 4 \\
Irritação persistente & 3 \\
Agitado & 2 \\
Nenhuma & 1 \\
\hline
\end{tabular}

\subsection{Exame físico}

A perda imediata da consciência é comum na lesão axonal difusa, enquanto a progressiva e rápida deterioração é sugestiva de edema cerebral difuso. As crianças com fontanelas e suturas não fixas são mais tolerantes às lesões expansivas intracranianas. Os sinais de massa em expansão podem não estar presentes até rápida descompensação ${ }^{(1)}$.
As crianças também são particularmente susceptíveis aos efeitos da lesão cerebral secundária que pode ser produzida por hipóxia, hipotensão com perfusão cerebral diminuída, convulsões e hipotermia. A adequada restauração do volume sangüíneo circulante é mandatória e a hipóxia deve ser evitada ${ }^{(4,11)}$.

A hipersensibilidade sobre a coluna cervical, edema, espasmo e torcicolo podem estar presentes, mas sua ausência não exclui lesão vertebral ${ }^{(4,11)}$.

A ausência de sinais externos de trauma ( hematomas, equimoses, escoriações) não excluem a presença de lesões internas no tronco ${ }^{(1,4)}$.

A distensão abdominal devido a distensão gástrica e a lesão de nervos intercostais devida a fraturas de costelas inferiores podem simular peritonite. A descompressão gástrica assim como a vesical facilitam a avaliação abdominal ${ }^{(1,4)}$.

A presença de instabilidade pélvica pode ser determinada pela compressão das espinhas ilíacas ântero-superiores e da sínfise púbica ${ }^{(11)}$.

Deve ser levada em conta a perfusão sanguínea das extremidades (avaliada pela coloração, temperatura e pulsos) e a presença de deformidades nos membros, sugerindo fraturas. Deve ser realizada a palpação cuidadosa de todos os ossos. No caso de fraturas de membros, a simples tentativa de redução restaura o fluxo sangüíneo e deve ser apropriadamente seguida de enfaixamento simples ou tração ${ }^{(1)}$.

Os ferimentos em extremidades devem ser cuidadosamente inspecionados, identificando-se o grau de lesão dos tecidos moles, a integridade muscular e dos tendões e a presença ou não de fraturas associadas. Até prova em contrário, qualquer desses ferimentos em extremidades pode representar uma fratura exposta. Quando próximos às articulações, deve ser verificada a presença de continuidade, o que irá alterar a conduta.

\subsection{Exames laboratoriais}

A medida seriada do hematócrito estima a extensão da perda sanguínea continuada, tão logo seja mantida a estabilidade hemodinâmica ${ }^{(4)}$.

As dosagens de transaminases séricas e amilase são importantes indícios de contusão, respectivamente, do fígado e do baço (que é contíguo à cauda do pâncreas) ${ }^{(4)}$.

A urina macroscopicamente hematúrica ou que contenha mais de 20 hemácias por campo, no exame microscópico, sugere lesão renal ${ }^{(12)}$. A hematúria é também um marcador da gravidade do trauma, uma vez 
que os rins são órgãos bem protegidos, e está associada com outras lesões intra-abdominais, em $80 \%$ dos $\operatorname{casos}^{(4)}$.

\subsection{Exames radiológicos}

A avaliação radiológica básica é realizada com radiografias da coluna cervical (antero-posterior e perfil), tórax e bacia (ambas antero-posteriores) $)^{(1)}$.

A radiografia da coluna cervical em perfil não pode excluir lesão da medula espinhal (não sendo prérequisito para a intubação endotraqueal de emergência, uma vez indicada, porém devem-se tomar precauções para a imobilização cervical) e também não pode definitivamente afastar qualquer anormalidade óssea, particularmente a fratura do odontóide, que é a mais comum na criança. Na presença de forte suspeita da coluna cervical, devemos realizar a tomografia computadorizada, que pode se seguir à tomografia de crânio, quando esta também estiver indicada ${ }^{(4)}$.

A radiografia simples de crânio é um pobre marcador de lesão cerebral e não deve fazer parte da avaliação inicial da criança comatosa, a não ser na suspeita de fratura craniana com afundamento ${ }^{(1)}$.

A tomografia computadorizada de crânio, geralmente, é o primeiro exame na avaliação da criança com significante traumatismo craniano (escala de coma de Adelaide menor ou igual a 13 ou perda da consciência maior que 05 minutos) ou sinais de aumento da pressão intracraniana (cefaléia intensa, sonolência e vômitos persistentes) e deve ser repetida em 24 a 48 horas após a admissão para aquelas crianças que permanecem comatosas, para determinar se as lesões previamente identificadas progrediram ou se apareceu uma lesão que ainda não tinha sido identificada ${ }^{(4,11)}$.

A tomografia computadorizada do abdome tem sua indicação liberada na avaliação do trauma abdominal contuso $^{(4,11)}$. Uma tomografia abdominal com duplo ou triplo contraste (via oral, endovenosa e por enema), incluindo o tórax inferior, deve ser realizada, quando o mecanismo de trauma sugerir que significante lesão intra-abdominal pode estar presente. Normalmente, é necessário o uso de sedação, pois a criança não deve se mover durante a realização do exame ${ }^{(11)}$.

Lembrar que nenhuma criança deve ser submetida a investigação radiológica se não estiver hemodinamicamente estável ou continuamente monitorizada e assistida por um médico capaz de estabelecer uma via aérea definitiva, particularmente se for usado algum sedativo ou bloqueador muscular para permitir a realização dos exames ${ }^{(4,11)}$.
As radiografias para diagnóstico de fraturas devem ser realizadas conforme suspeita clínica ou pelo mecanismo de lesão. Eventualmente, também são realizadas radiografias do lado não lesado para estudos comparativos.

Ultimamente, o ultras-som tem sido utilizado na própria sala de atendimento ao politraumatizado por ser um exame não invasivo, rápido e fácil de ser realizado e a baixo custo e, com a vantagem de realização seriada. É um método que tem sido utilizado para rastreamento, determinando a presença e a quantidade de líquido intraperitoneal, não interessando especificamente quais as lesões que ocorreram ${ }^{(33)}$. Seu real papel no atendimento inicial entre a tomografia computadorizada de abdome e o lavado peritoneal diagnóstico está por se determinar ${ }^{(34)}$.

\subsection{Lavado peritoneal diagnóstico}

Raramente é útil na avaliação do trauma abdominal contuso em crianças, já que a necessidade de laparotomia é determinada não pela presença ou ausência de sangue intraperitoneal, mas, pela necessidade de transfusão continuada ${ }^{(4,11)}$.

A maior parte das lacerações hepáticas, esplênicas e renais cicatrizam espontaneamente, sem a necessidade de laparotomia, após adequado estadiamento da lesão na tomografia de abdome ${ }^{(35)}$.

Algumas indicações desse exame são: choque inexplicado, crianças com trauma cranioencefálico que não pode ser submetida a tomografia abdominal, ferimentos penetrantes abaixo do nível dos mamilos, anteriormente, crianças que serão submetidas a anestesia geral para tratamento cirúrgico de lesões intracranianas ou musculoesqueléticas ${ }^{(8)}$.

Tecnicamente, esse exame deve ser realizado após prévia sondagem naso ou orogástrica e vesical, com incisão cutânea abaixo do umbigo.Utilizar um cateter de diálise de tamanho pediátrico e infundir 10 $\mathrm{ml} / \mathrm{Kg}$ de solução fisiológica, de preferência aquecida, até $39^{\circ} \mathrm{C}^{(1,11)}$.

A interpretação é feita da mesma maneira que no adulto, ou seja, mais de 100.000 hemácias por campo; presença de bile, conteúdo entérico, fezes ou fibras vegetais; número de leucócitos maior que 500 por $\mathrm{ml}$ e presença de bactérias no Gram ${ }^{(11)}$.

\subsection{Indicações cirúrgicas no trauma pediátrico}

No trauma contuso, as indicações de tratamento cirúrgico são: instabilidade hemodinâmica, apesar de adequada ressuscitação volêmica; necessidade 
transfusional maior que 50\% do volume sangüíneo estimado; sinais inequívocos de peritonite no exame físico; evidência endoscópica de ferimento retal; evidência radiológica de ar intra ou retroperitoneal; evidência radiológica de perfuração gastrintestinal; evidência radiológica de ruptura intraperitoneal da bexiga; evidência radiológica de lesão do pedículo renal; evidência radiológica de transecção pancreática; efluído da lavagem peritoneal contendo bile, bactérias, fezes ou mais de 500 leucócitos por $\mathrm{ml}^{(8,11)}$.

Nos traumas penetrantes, as indicações de cirurgia são: todos os ferimentos por arma de fogo em que haja suspeita de violação do peritônio; todos os ferimentos por arma branca, associados com evisceração e na vigência de sangue no estômago, urina ou reto; sinais físicos de choque ou peritonite; evidência radiológica de ar intra ou retroperitoneal; fluido da lavagem peritoneal contendo bile, bactéria, fezes ou mais de 500 leucócitos po $\mathrm{ml}^{(8,11)}$.

\subsection{Condutas na urgência}

\subsubsection{Trauma cranioencefálico}

Os sinais de lesão cerebral difusa em crianças podem incluir a perda inicial da consciência e a presença de pupilas fixas e dilatadas. Ainda que estes sinais sejam de prognóstico ruim no traumatismo cranioencefálico de adultos, por se relacionarem a lesões do tronco cerebral, nas crianças, podem se relacionar a graus variados de lesão, podendo, inclusive, ter recuperação neurológica completa. Por isso, crianças com escore da Escala de Coma de Glasgow, entre 05 e 08 , têm mortalidade baixa $(<35 \%)$ e morbidade menor que os adultos com a mesma pontuação na escala de Glasgow ${ }^{(14)}$.

Os vômitos e amnésia são mais comuns após trauma cranioencefálico em crianças e não necessariamente implicam em aumento da pressão intracraniana, porém, se persistirem, devem ser investigados com tomografia computadorizada de crânio ${ }^{(4,11,14)}$.

As convulsões pós-trauma são comuns e usualmente autolimitadas, não requerendo tratamento específico. As crises convulsivas persistentes indicam a ocorrência de patologia intracraniana grave ${ }^{(1,4,11)}$.

Os hematomas extradural e subdural, com volume suficiente para causar efeito de massa, requerem cirurgia. Porém, as fontanelas abertas e as linhas de suturas móveis tornam o crânio mais tolerante à presença de uma lesão expansiva. Os sinais de massa expansiva intracraniana podem estar ocultos até que rápida descompensação ocorra. Assim, as crianças, mesmo as que não estão em coma, mas que apresentem fontanela abaulada ou diástase de suturas, devem ser agressivamente avaliadas e tratadas ${ }^{(11,14)}$.

As crianças tendem a ter menos lesões focais do que os adultos, porém a frequiência de aumento da pressão intracraniana devida ao edema cerebral é mais comum $^{(11,14)}$. Assim sendo, a monitorização da pressão intracraniana deve ser considerada mais precocemente, principalmente em crianças com escala de coma de Glasgow, menor que 08 ou com escores motores de 01 ou 02 e, naquelas crianças que requerem reposição abundante de volume, com cirurgia abdominal ou torácica devida a risco de vida iminente ou, ainda, quando a estabilização e avaliação forem prolongadas ${ }^{(11)}$.

As fraturas cranianas lineares têm tratamento expectante. As fraturas abertas (com exposição de massa encefálica) e as fraturas com afundamento, que invadem a caixa craniana por uma distância igual à espessura da tábua óssea, requerem antibioticoterapia e tratamento cirúrgico. Suspeita-se de fraturas da base do crânio na vigência dos seguintes sinais clínicos: olhos de "guaxinim" (equimose periorbital), sinal de "Battle" (equimose do mastóide), hemotímpano e oto ou rinorragia com fluido cérebro-espinhal, já que os exames radiológicos raramente são diagnósticos. Na presença de fístula liquórica, não devem ser dados antibióticos, a não ser que haja febre, e o tratamento cirúrgico só está indicado naqueles casos em que a drenagem não cessa após 02 a 03 semanas $^{(4)}$.

Lembrar que as doses dos medicamentos utilizados no traumatismos cranioencefálicos devem ser ajustadas de acordo com o peso da criança: ${ }^{(11)}$

- diazepan - 0,25 mg/kg, em "bolus" lento endovenoso;

- fenitoína - 15 a $20 \mathrm{mg} / \mathrm{kg}$, sendo a dose de ataque de 0,5 a $1,5 \mathrm{ml} / \mathrm{kg} /$ minuto e manutenção de 4 a7 mg/kg/dia;

- manitol - 0,5 a 1,0 g/kg. Normalmente não utilizado, pois pode piorar a hipovolemia devido a diurese osmótica, aumentando a lesão cerebral secundária:

- fenobarbital - 15 a $20 \mathrm{mg} / \mathrm{kg}$ (dose de ataque) e $5 \mathrm{mg} / \mathrm{kg} / \mathrm{dia}$ (dose de manutenção).

As crianças têm uma recuperação do trauma cranioencefálico melhor que os adultos. Essa vantagem deixa de existir, se houver lesões associadas graves o bastante para causar hipotensão ou hipóxia ${ }^{(36)}$. As crianças menores de 03 anos têm pior resultado no trauma cranioencefálico grave do que crianças mais velhas $^{(1)}$. 


\subsubsection{Lesão medular}

A região cervical é a mais freqüentemente afetada. Metade dos pacientes morrem antes de chegar ao hospital ou durante a hospitalização. Dos restantes, a maioria permanece incapacitada, com pouca esperança de recuperação, apesar das recentes evidências de que altas doses de metilpredinisolona $(30 \mathrm{mg} / \mathrm{kg}$ em 15 minutos, seguido do uso de $5,4 \mathrm{mg} / \mathrm{kg} /$ hora nas próximas 23 horas) dadas até 08 horas após o trauma podem ter algum efeito na lesão primária ${ }^{(4)}$. Após mais de 08 horas da lesão, o uso de metilprednisolona não é recomendado. Existem vários estudos em andamento para melhor definição quanto ao uso de corticóides no trauma raquimedular ${ }^{(11,37)}$.

O tratamento é realizado, enfocando o choque neurogênico, que, tipicamente, está presente no choque medular (reversível) e na secção medular completa (irreversível). As fraturas vertebrais associadas, que, freqüentemente, são estáveis, são tratadas por imobilização contínua até a cicatrização completa ${ }^{(1)}$.

Lembrar que a presença de lesão medular sem anormalidades radiológicas é mais comum em crianças do que em adultos. Cerca de dois terços dos casos de crianças com lesão medular têm radiografias normais. Se há suspeita de lesão medular, baseada no mecanismo de trauma e no exame neurológico, a radiografia normal não exclui lesão medular ${ }^{(38,39)}$. Na dúvida quanto à integridade da coluna cervical, devemos manter a imobilização da cabeça e do pescoço e prosseguir na investigação com tomografia computadorizada ou ressonância nuclear magnética.

\subsection{Tórax}

A grande maioria das lesões são tratadas conservadoramente ou por drenagem pleural. Na técnica de drenagem pleural, devemos criar um túnel de adequada extensão, pois a fina parede torácica da criança não propicia um selo efetivo ao redor do dreno ${ }^{(4)}$. Normalmente, fazemos uma incisão na pele, um espaço intercostal abaixo do espaço intercostal que será aberto para a introdução do dreno pleural(ver Figura 7).

A contusão pulmonar, embora possa ocorrer na ausência de fraturas costais, não é freqüente e seu tratamento é expectante ${ }^{(1,40)}$.

A insuficiência respiratória pós-traumática é encontrada na presença de contusão pulmonar complicada com aspiração gástrica ou quando a ressuscitação inicial é complicada com hiper-hidratação. Os corticóides não são benéficos nesta condição, podendo mesmo piorar o resultado nos pacientes com aspiração gástrica ${ }^{(4)}$.
A asfixia traumática é mais freqüente em crianças e nenhum tratamento é requerido, porém reflete a extrema força aplicada no tórax, devendo-se suspeitar de lesões internas ${ }^{(4)}$.

\subsubsection{Abdome}

As lesões hepáticas, esplênicas e renais, geralmente, são autolimitadas, estando a laparotomia reservada para pacientes com choque circulatório sem resposta à reposição volêmica ou quando a necessidade transfusional excede metade da volemia em 24 horas. O tratamento não cirúrgico requer um mínimo de 07 a 10 dias de restrição ao leito, sendo que os primeiros 01 a 03 dias devem ser observados na Unidade de Terapia Intensiva ${ }^{(41)}$. Devem ser realizados hematócritos seriados e a excessiva palpação abdominal deve ser evitada. $\mathrm{O}$ exame tomográfico pode ser repetido em casos de dúvidas. Não devem ser feito exames tomográficos de rotina na alta hospitalar para documentar a evolução do quadro ${ }^{(4)}$.

O hematoma de parede duodenal resulta de um trauma direto no abdome superior, geralmente associado a quedas de bicicleta, pode ser suspeitado através da tomografia computadorizada ou de seriografia e têm tratamento conservador inicialmente com o uso de sonda nasogástrica e nutrição parenteral ${ }^{(11,42)}$.

Pseudocisto de pâncreas ocorre com maior freqüência que no adulto e é suspeitado na presença de massa epigástrica dolorosa, cerca de 30 a 05 dias após trauma no abdome superior, sendo tratado com nutrição parenteral prolongada por 06 a 08 semanas, quando se realiza a drenagem cirúrgica ${ }^{(4,11)}$.

Crianças com o "sinal do cinto de segurança" no abdome, pela colocação inapropriadamente alta da porção abdominal do cinto de segurança, particularmente aquelas com fratura de vértebras lombares por flexão, têm alta taxa de lesões gastrintestinais associadas, particularmente a ruptura direta da víscera ou sua avulsão do mesentério. Deve-se ficar atento nestes casos, para a indicação precoce de cirurgia ${ }^{(43,44)}$.

\subsubsection{Extremidades}

A estabilização precoce diminui o desconforto do paciente e limita a perda sanguínea. O tratamento conservador predomina em casos de fratura de clavícula, extremidades superiores, tíbia e fêmur. Neste tratamento, a redução inicial pode permitir eventuais desvios (exceto os rotacionais), pois a remodelação óssea os corrige gradativamente ${ }^{(11)}$.

Nas fraturas de fêmur, tem-se aumentado o uso de fixadores externos (crianças em idade escolar) e hastes intramedulares (em adolescentes), o que dimi- 
nui o tempo de recuperação, com retorno mais rápido às atividades habituais ${ }^{(4)}$.

O tratamento cirúrgico é realizado em casos de fraturas expostas (para desbridamento, lavagem e fixação). As fraturas supracondilianas do cotovelo com desvio (que têm maior associação com lesão vascular isquêmica) e fraturas envolvendo a cartilagem de crescimento devem ser reduzidas anatomicamente através de cirurgia ${ }^{(4,11)}$.

\subsection{Abuso físico contra crianças}

É definido como qualquer lesão não acidental devido a ações de pais, parentes ou familiares ${ }^{(1)}$.

A história e avaliação cuidadosa da criança com suspeita de abuso é fundamental para impedir a morte eventual, especialmente em crianças menores de 01 ano $^{(1,11)} \mathrm{O}$ médico deve suspeitar de abuso se houver: discrepância entre a história e o grau de lesões físicas; intervalo prolongado entre o tempo de lesão e a con- sulta médica; história de traumas repetidos, tratados em locais diferentes; pais que respondem inapropriadamente ou que não seguem as recomendações médicas; história de lesões diferentes ou alteradas entre pais ou familiares.

Há certos achados físicos que sugerem abuso físico e sugerem investigação mais pormenorizada: múltiplos hematomas subdurais, sem história significativa de trauma; hemorragia retiniana; lesões periorais; ruptura de víscera interna sem antecedente de trauma contuso; trauma em região cervical genital ou perianal; evidência de lesões freqüentes como cicatrizes e fraturas consolidadas nas radiografias; fraturas de ossos longos em crianças menores de 03 anos; lesões bizarras como mordeduras, queimaduras por cigarros ou marcas de corda; queimaduras de 2 e 3 graus repetidas em áreas não usuais ${ }^{(1,11)}$.

É obrigação do médico denunciar os casos suspeitos de abuso físico às autoridades judiciais ${ }^{(1,11)}$.

PEREIRA JR GA; ANDREGHETTO AC; BASILE-FILHO A \& ANDRADE JI. TITULO EM INGLES. Medicina, Ribeirão Preto, 32: 262-281, july/sept. 1999.

ABSTRACT: The purpose of this chapter is to present those principles of care that impact the integrity of the airway, breathing, and circulation or influence the priorities of advanced trauma life support for the pediatric trauma patient. Assessment and treatment decisions must be made quickly to prevent progression and deterioration to respiratory failure and cardiopulmonary arrest. Definitive evaluation and initial treatment of most other injuries can be safely undertaken after ventilation, oxygenation, and perfusion have been restored. Such definitive care is provided upon completion of the secondary survey, a detailed head-to-toe examination for detection of specific injuries.

UNITERMS: Pediatrics. Injuries. Traumatology.

\section{REFERÊNCIAS BIBLIOGRÁFICAS}

1 - ADVANCED TRAUMA LIFE SUPPORT. Student manual. Committee on Trauma. American College of Surgeons, Chicago, p. $1-406,1993$.

2 - KLEM AS; POLLACK MM \& GLASS NL. Resource use, efficiency and outcome predition in pedriatric intensive care of trauma patients. J Trauma 30: 32-36, 1990.

3 - STYLIANOS S. Late sequelae of major trauma in children. Pediatr Clin North Am 45: 853-859, 1998.

4 - COOPER A. Pediatric Trauma (Basic Principles). In: AYRES SM, GRENVIK A, HOLBROOK PR \& SHOEMAKER WC, eds. Textbook of Critical Care, 3rd ed, WB Saunders, Philadelphia, p. 1465-1475, 1995.
5 - PEDIATRIC ADVANCED LIFE SUPPORT. Textbook of american academy of pediatrics. American Heart Association, Chicago, 1994.

6 - SPARNON AL \& FORD WDA. Bicicle handlebar injuries in children. J Pediatr Surg 21: 118-119, 1986.

7 - ROSHKOW JE; HALLER JO \& HOTSON GC. Imaging evaluation of children after falls from a height. Review of 45 cases. Radiology 175: 359-363, 1990.

8 - KNUDSON P. Pediatric trauma. Trauma manual, San Francisco General Hospital. University of California, 1995.

9 - GREENSPAN AI \& MACKENZIE EJ. Functional outcome after pediatric head injury. Pediatrics 94: 425-432, 1994.

10 - MORONTI ML; WILLIAMS JÁ \& EICHELBERGER MR. The in- 
jured child: an approach to care. Pediatr Clin North Am 41: 1201-1206, 1994.

11 - ADVANCED TRAUMA LIFE SUPPORT. Student manual. Committee on Trauma. American College of Surgeons, Chicago, p. 353-376, 1997.

12 - STANCIN T; TAYLOR HG; THOMPSON GH; WADE S; DROTAR $D$ \& YEATES KO. Acute psychosocial impact of pediatric orthopedic trauma with and without accompanying brain injuries. J Trauma 45: 1031-1038, 1998.

13 - GRUSKIN KD \& SCHUTZMAN AS. Head trauma in children younger than 2 years: are there predictors form complications ? Arch Pediatr Adolesc Med 153: 15-20, 1999.

14 - FUNDAMENTAL CRITICAL CARE SUPPORT. Course Text, $2^{\text {th }}$ ed. Society of Critical Care Medicine, p. 1- 346, 1997.

15 - TEPAS JJ; MOLLITT DL; TALBERT JL \& BRYANT M. The pediatric trauma score as a predictor of injury severity in the injured child. J Pediatr Surg 22: 14 - 18, 1987.

16 - CHAMPION HR; SACCO WJ \& COPES WS.. A revision of the Trauma Score. J Trauma 29: 623 - 629, 1989.

17 - ADVANCED CARDIAC LIFE SUPPORT. Student manual.. $2^{\text {th }}$ ed. American Heart Association, Chicago, 1997.

18 - KAUFMANN CR; RIVARA FP \& MAIER RV. Pediatric trauma: Need for surgical management. J Trauma 29: 1120-1126, 1989.

19 - DYKES EH; SPENCE LJ \& YOUNG JG. Preventable pediatric trauma deaths in a metropolitan region. J Pediatr Surg 24: 107-111, 1989.

20 - GERARDI MJ; SACHETTI AD; CANTOR RM; SANTAMARIA JP; GAUSCHE M; LUCID W \& FOLTIN GL. Rapid sequence intubation of the pediatric patient. Pediatric Emergency Medicine Committee of the American College of Emergency Physicians. Ann Emerg Med 28: 55 - 60, 1996.

21 - TOBIAS JD. Airway management for pediatric emergencies. Pediatr Ann 25: 317 -20, 323-328, 1996.

22 - DRINKER CK; DRINKER KR \& LUND CC. The circulation in the mammalian bone marrow. Am J Physiol 62: 1 -92, 1922.

23 - TOCANTINS LM. Rapid absorption of substances injected into the bone marrow. Proc Soc Exp Biol Med 45: $292-$ 296, 1940.

24 - TOCANTINS LM \& O'NEILL JF. Infusion of blood and others fluid into the general circulation via the bone marrow: technique and results. Surg Gynecol Obstet 73: 281-287, 1941.

25 - MEOLA F. Bone marrow infusions as a routine procedure in children. J Pediatr 25: 13 - 17, 1944.

26 - BAILEY H. Bone marrow as a site for the receptions of infusions, transfusion, and anaesthesic agents: a review of the present position. Br Med J 1: 181 - 182, 1944.

27 - VALDES MM. Intraosseous fluid administration in emergencies. Lancet 1: 1235 - 1236, 1977.

28 - SAWYER RW; BODAI BI, BLAISDELL FW \& MCCOURT MM. The current status of intraosseous infusion. J Am Coll Surg 179: $353-360,1994$.
29 - ROSSETTI V; THOMPSON BM \& MILLER J. Intraosseous infusion: an alternative route of pediatric intravascular access. Ann Emerg Med 14: 885 - 888, 1995.

30 - HOLLIDAY MA \& SEGAR WE. Maintenance need for water in parenteral fluid therapy. Pediatrics 19: 823-832, 1957.

31 - SIMPSON DA; COCKINGTON RA; HANIEH A; RAFTOS J \& REILLY PL. Head injuries in infants and young children: the value of the Pediatric Coma Scale. Childs Nerv Syst 7: 183 $-190,1991$.

32 - TEASDALE G \& JENNETT B. Assessment of coma and impaired consciousness: a pratical scale. Lancet 2: $81-84$, 1974.

33 - BODE PJ; NIEZEN RA; VAN VUGT AB \& SCHIPPER J. Abdominal ultrasound as a reliable indicator for conclusive laparotomy in blunt abdominal trauma. J Trauma 34: 27 - 31, 1993.

34 - FELICIANO DV. Diagnostic modalities in abdominal trauma. Peritoneal lavage, ultrasonography, computed tomography scanning, and arteriography. Surg Clin North Am 71: 241 $-255,1991$.

35 - LUNA GK \& DELLINGER EP. Nonoperative observation therapy for splenic injuries: a safe therapeutic option. Am J Surg 153: 462 - 468, 1987.

36 - CHESNUT RM; MARSHALL LF; KLAUBER MR; BLUNT BA; BALDWIN N; EISENBERG HM; JANE JA; MARMAROU A \& FOULKES MA. The role of secondary brain injury in determining outcome from severe head injury. J Trauma 43: 216 $-222,1993$.

37 - WILBERGER JE. Diagnosis and management of spinal cord trauma. J Neurotrauma 8: 75 - 86, 1991.

38 - WOODRING JH \& LEE C. Limitations of cervical radiography in the evaluation of cervical trauma. J Trauma 34: $32-39$, 1993.

39 - PANG D \& WILBERGER JE. Spinal cord injury without radiographic abnormalities in children. J Neurosurgery 57: 114 $-129,1982$.

40 - GARCIA VF; GOTSCHALL CS; EICHELBERGER MR \& BOWMAN LM. Rib fractures in children: a marker of severe trauma. J Trauma 30: 695 - 700, 1990.

41 - KELLER MS \& VANE DW. Management of blunt splenic injury: comparison of pediatric and adult. J Pediatr Surg 153: 462 - 468, 1987.

42 - ASENSIO JÁ; FELICIANO DV; BRITT LD \& KERSTEIN MD. Management of duodenal injuries. Curr Probl Surg 30: 1021 $-1100,1993$.

43 - ANDERSON PA; RIVARA FP; MAIER RV \& DRAKE C. The epidemiology of seat belt-associated injuries. J Trauma 31 : $60-67,1991$.

44 - ASBUN HJ; IRANI H; ROE EJ \& BLOCH JH. Intraabdominal seat belt injury. J Trauma 30: $189-193,1990$.

Recebido para publicação em 11/8/99

Aprovado para publicação em 14/9/99 